OPEN ACCESS

Edited by:

Satyendra Chandra Tripathi, All India Institute of Medical Sciences

Nagpur, India

Reviewed by:

Letizia De Chiara,

University of Florence, Italy

Saurav Kumar,

Fred Hutchinson Cancer Research

Center, United States

*Correspondence:

Bushra Ateed

bushra@iitk.ac.in

Specialty section:

This article was submitted to

Molecular Diagnostics and

Therapeutics,

a section of the journal

Frontiers in Molecular Biosciences

Received: 05 March 2020

Accepted: 02 June 2020

Published: 10 July 2020

Citation:

Tiwari R, Manzar N and Ateeq B (2020) Dynamics of Cellular Plasticity

in Prostate Cancer Progression.

Front. Mol. Biosci. 7:130

doi: $10.3389 /$ fmolb.2020.00130

\section{Dynamics of Cellular Plasticity in Prostate Cancer Progression}

\author{
Ritika Tiwari, Nishat Manzar and Bushra Ateeq* \\ Molecular Oncology Laboratory, Department of Biological Sciences and Bioengineering, Indian Institute of Technology \\ Kanpur, Kanpur, India
}

Despite the current advances in the treatment for prostate cancer, the patients often develop resistance to the conventional therapeutic interventions. Therapy-induced drug resistance and tumor progression have been associated with cellular plasticity acquired due to reprogramming at the molecular and phenotypic levels. The plasticity of the tumor cells is mainly governed by two factors: cell-intrinsic and cell-extrinsic. The cell-intrinsic factors involve alteration in the genetic or epigenetic regulators, while cell-extrinsic factors include microenvironmental cues and drug-induced selective pressure. Epithelial-mesenchymal transition (EMT) and stemness are two important hallmarks that dictate cellular plasticity in multiple cancer types including prostate. Emerging evidence has also pinpointed the role of tumor cell plasticity in driving anti-androgen induced neuroendocrine prostate cancer (NEPC), a lethal and therapy-resistant subtype. In this review, we discuss the role of cellular plasticity manifested due to genetic, epigenetic alterations and cues from the tumor microenvironment, and their role in driving therapy resistant prostate cancer.

Keywords: prostate cancer, ADT, cellular plasticity, EMT, stemness, drug resistance, NEPC

\section{INTRODUCTION}

Prostate cancer (PCa) represents a highly heterogenous disease with diverse range of molecular alterations defining its subclasses. These molecular alterations include somatic or germline mutations, focal deletions, amplifications, and gene fusions that entail the intra- and inter-patient heterogeneity and confer variable clinical outcomes. The major molecular subclasses include a variety of gene fusions involving ETS family transcription factors, namely ERG, ETV1/4, FLI1, and NDRG1; or RAF kinase rearrangements, upregulation of secretory protein SPINK1 and somatic mutations in SPOP, FOXA1, and IDH1 (Tomlins et al., 2005, 2008; Palanisamy et al., 2010; Cancer Genome Atlas Research, 2015; Bhatia and Ateeq, 2019). The androgen signaling plays a key role in development and maintenance of the prostate gland (Cunha et al., 1987; Cooke et al., 1991), while aberrant activation of this signaling has been linked to the initiation and metastatic progression of PCa (Gelmann, 2002; Culig and Santer, 2014; Tan et al., 2015). Thus, drugs that target biosynthesis of androgen or androgen receptor (AR) activity are often administered as the first line therapy also known as androgen deprivation therapy (ADT). However, the disease inadvertently progresses to an advanced stage, castrate-resistant prostate cancer (CRPC) (Cher et al., 1996; Gregory et al., 2001; Chen et al., 2004; Grasso et al., 2012; Robinson et al., 2015). At CRPC stage, the cancer cells bypass their dependency on the androgen signaling by various mechanisms such as somatic mutations or amplification of $A R$ gene, constitutively active splice variants (AR-V7 and ARv567es), mutations in the ligand binding domain of AR (F877L and T878A), or activation 
of androgen-regulated genes via glucocorticoid receptor (Taplin et al., 1995; Arora et al., 2013; Antonarakis et al., 2014). The androgen biosynthesis inhibitor, abiraterone and nextgeneration AR-antagonists, enzalutamide and apalutamide have been developed for the clinic management of CRPC patients (Scher et al., 2010; de Bono et al., 2011; Clegg et al., 2012). Although, AR-targeting therapies prolong the overall survival of the patients, nonetheless, resistance to these drugs often prevail leading to disease progression to an aggressive stage, also known as neuroendocrine prostate cancer (NEPC) (Aggarwal et al., 2018). The mechanism to overcome the acquired resistance toward anti-androgen therapy is frequently manifested by several molecular and phenotypic changes resulting in transition of androgen-independent CRPC to therapy-induced NEPC (Zou et al., 2017; Aggarwal et al., 2018; Soundararajan et al., 2018; Beltran et al., 2019). This dynamic transition provides multifaceted advantages to the cancer cells to overcome therapyinduced resistance and enable survival (Sun et al., 2012; Miao et al., 2017; Stylianou et al., 2019).

Cellular plasticity represents the dynamic transition of a cell between one state to another (Varga and Greten, 2017). The term "plasticity" was introduced to define the extensive reprogramming events happening in stem cells leading to cellular differentiation (Blau et al., 1985). This is a bidirectional process which involves changes both at the molecular and phenotypic levels of a cell. The cellular plasticity has been a key phenomenon that governs not only the developmental fate of the organism, but also serves as a driving force behind different malignancies, including PCa (Rothman and Jarriault, 2019; Yuan et al., 2019). During early embryonic development, the cellular plasticity helps the stem or progenitor cells to differentiate into different lineages while in the later stages of life, it maintains stem cell populations and regulates tissue repair (Wagers and Weissman, 2004). Several complex processes such as transcriptional regulation or epigenetic alterations are known to modulate the cellular identity and plasticity (Flavahan et al., 2017). Mounting evidence suggests that the genes involved in the embryonic development are frequently subverted or reactivated during malignant transformation of cells (Kalluri and Weinberg, 2009; Dempke et al., 2017). These acquired molecular attributes enable the tumor cells to elude the constraints of normal growth, thereby assisting them to thrive and sustain, escape therapeutic pressure and immune surveillance (Zou et al., 2017; Vitkin et al., 2019; Yuan et al., 2019). Likewise, in PCa, cellular plasticity aids the tumor cells to develop resistance against the targeted therapies in several different ways, for instance, by undergoing phenotypic conversions, cellular reprogramming and transition from one cell lineage to another (Beltran and Demichelis, 2015; Zou et al., 2017; Alumkal et al., 2020).

In this review, we discuss the importance of cellular plasticity in conferring intra-tumoral heterogeneity and its impact on disease progression and drug resistance. Further, we attempt to delineate the implications of cell-intrinsic and -extrinsic factors which govern the plasticity in tumor cells. Finally, we also summarize the novel therapeutic interventions used to target cellular plasticity in combating prostate cancer.

\section{INTRA-TUMORAL HETEROGENEITY AND CELLULAR PLASTICITY}

PCa exhibits high level of intra-tumor heterogeneity characterized by distinct sub-populations of the cancer cells, which is often a major confounding factor influencing disease progression (Boyd et al., 2012; Yadav et al., 2018). This intratumor heterogeneity offers a multifaceted advantage to the $\mathrm{PCa}$ cells such as disease progression, tumor dissemination, and driving resistance toward standard therapies such as chemotherapy, radiation or hormone therapy (Marjanovic et al., 2013). Two different models contributing to intra-tumoral heterogeneity in PCa have been generally accepted. In the clonal evolution model, tumors arise from a single cell of origin triggered in response to sequential oncogenic hits (Liu et al., 2009; Kreso and Dick, 2014). In cancer stem cell model, tumor cells originate from the differentiation of a small population of cancer stem cells (CSCs) or dedifferentiation of the existing cancer cells into CSCs to promote tumor growth and progression (Collins et al., 2005; Patrawala et al., 2006; Yadav et al., 2018). The neoplastic transformation via either of the proposed pathways give rise to genetically and phenotypically distinct cell types within same tumor (Poli et al., 2018). This morphological heterogeneity is responsible for the multifocality within the prostate tumor of the same patient. The multifocality has been reported in $\sim 50-90 \%$ of the PCa patients who underwent radical prostatectomy, and has been linked with higher grade, advanced stage and recurrence compared to unifocal prostate adenocarcinoma (Djavan et al., 1999). Multifocal tumors exhibit significant molecular heterogeneity in terms of copy number alterations (CNAs), single-nucleotide variants (SNVs), genomic rearrangements, and unique signatures of DNA damage and transcriptional dysregulation (Beltran and Demichelis, 2015; Boutros et al., 2015). Additionally, intra-tumoral variability involving distinct DNA methylation and histone modification patterns was found to be more pronounced in the advanced stage $\mathrm{PCa}$, suggesting association of epigenetic heterogeneity with poor clinical outcome (Seligson et al., 2005; Bianco-Miotto et al., 2010; Brocks et al., 2014). Thus, deciphering the molecular basis of the intra-tumor heterogeneity may provide an insight for better prognosis and the clinical management of PCa patients.

\section{EPITHELIAL-MESENCHYMAL TRANSITION MODULATES CELLULAR PLASTICITY IN PROSTATE CANCER}

The epithelial-mesenchymal transition (EMT) is the key phenomenon in embryonic development, nonetheless, it plays a pivotal role in maintaining tissue homeostasis as well as cancer progression (Nauseef and Henry, 2011). This complex process involves transition of a epithelial cell into a mesenchymal phenotype, characterized by reduced cell-cell adhesion and increased migratory properties (Lu and Kang, 2019). Moreover, tumors often exhibit co-existence of a subpopulation of cells in hybrid state harboring both epithelial and mesenchymal phenotypes (hybrid E/M state), further aiding the cancer cells 
to metastasize from primary to distant secondary sites (Tsai and Yang, 2013; Williams et al., 2019). During this reprogramming, the cancer cells secrete an array of enzymes which break down its attachment to the basement membrane followed by several phenotypic changes such as reorganization of actin cytoskeleton, leading to enhanced migratory and metastatic potential (Thiery et al., 2009). Multiple clinical evidence has associated enhanced mesenchymal features with high Gleason grade, shorter time to biochemical recurrence and increased metastasis in $\mathrm{PCa}$ (Cheng et al., 1996; Graham et al., 2008; Zhang et al., 2009; Figiel et al., 2017).

Several transcription factors (TFs) associated with EMT regulate cellular plasticity during embryonic development have been identified as the oncogenic determinants in the neoplastic transformation of prostate. For example, SRY-Box Transcription Factor 9 (SOX9) enables transition of fetal prostate epithelial cells into mesenchyme during embryogenesis and its high levels in advanced stage PCa has also been reported (Wang et al., 2008). Furthermore, Wnt/ $\beta$-catenin signaling which is linked with the initiation and progression of multiple cancers is also known to regulate expression of Sox9 (Clevers, 2006). Another key feature of EMT is the loss of adherens junction protein, E-Cadherin (ECad), a tumor suppressor required for maintaining the epithelial phenotype (Loh et al., 2019). Moreover, downregulation of E-Cad via Notch signaling is also known to promote drug resistance in PCa cells (Wang et al., 2017). In addition, zinc finger proteins belonging to Snail family transcriptional repressors, SNAI1 (SNAIL) and SNAI2 (SLUG), and zinc finger E-boxbinding homeobox 1 and 2 (ZEB1 and ZEB2) and Twist-related protein 1 (TWIST1) are the key TFs involved in EMT, which also downregulate E-Cad and upregulate various mesenchymal markers, namely $\mathrm{N}$-Cadherin (N-Cad), Vimentin (VIM) and Fibronectin (Jennbacken et al., 2010; Zhu and Kyprianou, 2010; Sun et al., 2012; Shiota et al., 2014; Zhifang et al., 2015; Miao et al., 2017). In a recent study, a positive feedback loop has been demonstrated between SOX4 and a scaffold protein Cullin 4B (CUL4B), wherein CUL4B induces the SOX4 expression via PRC2-mediated silencing of miR-204 and in turn SOX4 positively regulates the transcription of CUL4B, leading to enhanced proliferation and invasion of PCa cells. In addition, the CUL4B+/SOX4+ subset of PCa patients show activation of $\mathrm{Wnt} / \beta$-catenin signaling pathway and are associated with an aggressive disease and poor prognosis (Qi et al., 2019).

In $\mathrm{PCa}$, the selection pressure imposed by ADT has been well-known to potentiate EMT and stemness (Sun et al., 2012; Tsai et al., 2018). Importantly, androgen deprivation in mice implanted with human LuCaP35 prostate tumor induces the increased expression of $\mathrm{N}$-Cadherin (CDH2), VIM, ZEB1, TWIST1, and SLUG. Notably, a bidirectional negative feedback loop is generated between AR and Zeb1 which is involved in androgen deprivation induced EMT (Sun et al., 2012). Moreover, LNCaP cells treated with epigenetic drugs lead to upregulation of ZEB1 and reduced AR levels, whereas siRNA mediated ZEB1 silencing leads to increased expression of AR (Sun et al., 2012). Interestingly, enhanced expression of $Z E B 1$ due to copy number gain leads to direct transcriptional repression of miR-33a-5p in PCa cells, and contribute to an increase in EMT, invasion, migration and bone metastasis (Dai et al., 2019). Besides, miR33a-5p indirectly inhibits ZEB1 expression via targeting TGFBR1 and suppressing TGF- $\beta$ signaling, thus forming an indirect double-negative feedback loop. AR is also known to act as the direct transcriptional repressor of SNAIL, and its upregulation along with ZEB1/2, TWIST and Forkhead box protein C2 (FOXC2) has been reported as an adaptive response to androgen deprivation (Miao et al., 2017). Intriguingly, tumor grafts derived from PCa patients who underwent radical prostatectomy following neoadjuvant ADT (6-8 weeks of flutamide or lupron) exhibit mislocalization of E-Cad and elevated VIM expression (Zhao et al., 2013).

Conversely, ZEB2, another critical mediator of EMT shows AR mediated differential regulation in androgen dependent vs. independent manner. In androgen-dependent LNCaP cells, ZEB2 is positively regulated by AR and showed increased expression upon androgen stimulation while reduced expression in $A R$-silenced cells. In androgen-independent cell lines, such as PC3 and DU145, ectopic expression of AR leads to upregulation of miR-200a/miR-200b resulting in reduced expression of ZEB2 accompanied with diminished invasive potential (Jacob et al., 2014). This context-dependent AR mediated regulation of ZEB2 may be due to the differences in the levels and types of coregulatory proteins which modulate AR activity as an activator or repressor (Van De Wijngaart et al., 2012). In another study, miR-145 has been shown to post-transcriptionally suppress the expression of ZEB2 resulting in decreased invasion, migration and stemness in PCa cells (Ren et al., 2014). Moreover, ZEB2 acts as a direct transcriptional repressor of miR-145 and its downregulation in PC3 cells results in reduced bone invasion in mouse models, suggesting a double-negative feedback loop between ZEB2 and miR-145. Unlike SNAIL, which is an AR repressed gene, the SLUG expression was found to be upregulated by constitutively active AR signaling in a ligandindependent manner. Additionally, SLUG also serves as a novel co-activator of $\mathrm{AR}$ and enhances its transcriptional activity even in the absence of androgens (Wu et al., 2012). Another study has shown that siRNA-mediated AR silencing in PCa cells promoted migration and invasion via $\mathrm{C}-\mathrm{C}$ motif chemokine ligand 2 (CCL2)-dependent STAT3 activation and subsequent upregulation of EMT associated pathways (Izumi et al., 2013). In a follow-up study, targeting pSTAT3-CCL2 signaling with C-C chemokine receptor type 2 (CCR2) antagonists reversed the ADT induced cell invasion and macrophage infiltration in transgenic adenocarcinoma of the mouse prostate-C1 (TRAMP-C1) mouse tumors (Lin et al., 2013). One possible explanation could be that AR is known to directly regulate SPDEF (SAM pointed domaincontaining ETS transcription factor), a transcriptional repressor of CCL2, and ADT leads to reduced SPDEF expression resulting in elevated CCL2 levels (Tsai et al., 2018). Thus, the importance of AR-signaling in EMT is context-dependent in PCa and needs to be further delineated in order to understand the pathobiology of this disease and develop effective therapeutic approaches.

While EMT helps with the initial dissemination of the tumor cells, clinical manifestation of the metastases depends upon mesenchymal-epithelial transition (MET), which is crucial for the effective seeding and colonization of the disseminated 
tumor cells at the distant metastatic site (Nieto, 2013). For instance, the cross-talk between the metastasized PCa cells and stroma in liver show elevated expression of the E-Cad, possibly due to MET induced cellular plasticity (Yates et al., 2007). This dynamic transition through a spectrum of phenotypically different states could potentially regulate the initial dissemination of PCa cells followed by metastatic spread to the distant sites. However, more evidence is required to support the notion of EMT-MET axis in cellular reprogramming and may serve as a promising therapeutic strategy in targeting disease progression in prostate cancer.

\section{STEMNESS IMPARTS CELLULAR PLASTICITY IN PROSTATE CANCER}

The CSCs constitute a small population of tumor cells which has the potential to drive cancer progression, increased resistance to conventional therapies and ability to disseminate to distant organs (Soundararajan et al., 2018; Li and Shen, 2019). However, the theory about the exact origin of CSCs is still debatable. It has been suggested that CSCs are either derived directly from the normal stem cells or produced as a result of de-differentiation or trans-differentiation of the existing cancer cells (FriedmannMorvinski and Verma, 2014; Plaks et al., 2015).

The role of EMT in imparting stemness is much in contrast to its significance in the normal embryonic development, wherein it primarily governs the differentiation of stem cells into multiple lineages (Wang and Unternaehrer, 2019). EMT promoting transcription factors, such as ZEB1 is known to promote stemness in PCa (Wellner et al., 2009; Orellana-Serradell et al., 2018). Moreover, ectopic expression of platelet-derived growth factor D (PDGF-D) in PC3 cells lead to morphological changes associated with acquisition of EMT and increased clonogenicity and sphere-forming abilities. These cells also show enhanced expression of TFs associated with stemness such as Nanog, Oct4 and Sox2, Lin28B and members of polycomb repressor complex 2 (PRC2) (Kong et al., 2010). Moreover, human PCa derived LuCaP35 xenografts when subjected to ADT show concomitant higher expression of EMT as well as stem cell markers, namely WNT5a and WNT5b (Sun et al., 2012). Although EMT is known to promote tumorigenesis, a subpopulation of tumor cells with epithelial phenotype are reported to have high metastatic potential (Celia-Terrassa et al., 2012). Also, cells undergoing EMT have increased invasive ability but diminished capacity of establishing distant metastasis (Tsuji et al., 2008; Floor et al., 2011). Furthermore, it has been demonstrated that a subpopulation of cells with epithelial phenotype and high ECad expression, also shows enhanced stemness and self-renewal ability (Celia-Terrassa et al., 2012). Intriguingly, a recent study has shown the tumor promoting role of E-Cad in invasive ductal carcinomas of breast, wherein it promotes tumor growth and metastases (Padmanaban et al., 2019). However, E-Cad has been implicated majorly as a tumor-suppressor across multiple cancer types, and its loss is directly involved in imparting various oncogenic traits especially stemness and metastases (Frixen et al., 1991; Berx et al., 1995; Guilford, 1999; Onder et al., 2008).
The CSCs express a broad range of cell surface markers which distinguish them from the cells of other origins. For instance, prostate CSCs (PCSCs) harbor expression of several cell surface markers such as $\mathrm{CD}_{4} 4^{+} \alpha 2 \beta 1^{\text {hi }} \mathrm{CD} 133^{+}$(Collins et al., 2005). The $\mathrm{CD}_{4} 4^{+}$cell population derived from multiple PCa cell lines and xenograft tumors showed increased tumorigenic and metastatic potential along with enhanced expression of stemness promoting TFs factors namely, Oct-3/4, Bmi and $\beta$-catenin (Patrawala et al., 2006). The CD44 is considered as a putative marker for PCSCs and primarily expressed on the surface of basal and rare neuroendocrine cells, whereas the luminal cells lack its expression (Palapattu et al., 2009; Wang and Shen, 2011; Guo et al., 2012). The pluripotent basal cells differentiate to luminal and neuroendocrine cells, and hence been proposed to have high tumorigenic potential and could serve as cells of origin in prostate carcinogenesis (Goldstein et al., 2010; Taylor et al., 2012). It has also been reported that luminal multilineage progenitor cells are the cells of origin and basal cells transition to luminal cells in order to promote tumorigenesis (Karthaus et al., 2014; Wang et al., 2014). Further, ABCG2, a well-known ATP-binding cassette transporter ( $\mathrm{ABC}$ transporter) associated with drug efflux is known to be highly expressed in PCSCs and drives resistance to therapeutic agents (Huss et al., 2005).

Similar to EMT, the dedifferentiated PCSCs show inverse correlation with AR signaling. For instance, $\mathrm{PSA}^{-/ 1}$ (PSAnegative or low) cell population exhibits gene expression profile similar to stem cells, harbors enhanced self-renewing potential and resistance to ADT and chemotherapeutic agents (Qin et al., 2012). The PCSCs isolated from AR-negative DU145 cells show higher expression of CD44, CD24, integrin $\alpha 2 \beta 1$, cellular reprogramming factor SOX2, and exhibit tumorinitiating potential and self-renewal ability (Rybak et al., 2011; Rybak and Tang, 2013). Similarly, a subpopulation of tumor cells isolated from prostatectomy specimens express higher levels of tumor-associated calcium signal transducer 2 (Trop2), CD44, and CD49f, and show increased sphere-forming ability and regeneration capability in mice (Garraway et al., 2010). Conclusively, a consensus regarding a specific set of markers to identify PCSCs is still lacking and in-depth study is warranted to identify the defined markers for multipotent tumor progenitor cells in order to develop better therapeutic strategies.

\section{THERAPY-INDUCED CELLULAR PLASTICITY AND DISEASE PROGRESSION}

The cancer cells evade the drug induced therapeutic pressure by modulating cellular plasticity which is one of the major mechanisms posing significant challenges for PCa treatment (Boumahdi and de Sauvage, 2019). The plasticity of the tumor cells provides a survival advantage by developing alternate adaptive pathways, independent of the targeted therapies. As mentioned previously, ADT is administered as the standard care for the treatment of men with prostate cancer. One of the main mechanisms of eluding AR-targeted therapy or ADT is the transdifferentiation of the AR-dependent PCa cells to ARindependent neuroendocrine (NE)-like phenotype (Lin et al., 
2014). Transdifferentiation is a process wherein a differentiated cell type transitions to another lineage to evade the therapyassociated drug pressure (Davies et al., 2018).

This transition process in response to therapy is often driven by a distinct transcriptional or epigenetic reprogramming of the tumor cells (Yuan et al., 2019). Recent evidence highlighted the role of EMT and stemness as important driving factors for the cellular plasticity during the neuroendocrine transdifferentiation (Soundararajan et al., 2018). Several transcription factors which are directly involved in regulating EMT are also key players involved in neuroendocrine transdifferentiation. For instance, overexpression of SNAIL imparts cellular plasticity by downregulating the E-Cad expression and enhancing the expression of neuroendocrine differentiation markers, namely, ENO2 and CHGA (McKeithen et al., 2010; Barnett et al., 2011). Similarly, neuroendocrine transdifferentiation of patient-derived LTL331 xenograft model also exhibits higher levels of SNAI1 and ZEB1 (Akamatsu et al., 2015).

The PCa cells have the ability to dedifferentiate into CSCs exhibiting tumor-initiating potential with an invasive phenotype and resistance to AR-antagonists. These reprogrammed cells when exposed to androgens in culture showed reactivation of the AR signaling, indicating the active dynamics of the cellular plasticity in response to the external cues (Nouri et al., 2017). The advanced neuroendocrine tumors such as small cell NE-like carcinomas are often characterized to have stem celllike features (Ellis and Loda, 2015). Moreover, pluripotency factors, SOX2 and SOX11 have also been implicated in ARindependent NE-like tumors (Blee and Huang, 2019). Recent evidence suggested that BRN2 co-regulates the transcriptional landscape of the SOX2 and is essentially overexpressed in NEPC patients (Bishop et al., 2017). The elevated levels of EMT modulator ZEB1 also induces stem-cell like properties in PCa cells along with concomitant upregulation of SOX2 (Li et al., 2014). Apart from the critical role of EMT and CSCs in evading therapeutic pressure, several inherent factors also play an important role in imparting resistance to the therapy. For example, genetically engineered mouse (GEM) model with inactivation of Pten and Tp53 failed to show any response to abiraterone, and exhibited accelerated progression to treatment-induced neuroendocrine differentiation (Zou et al., 2017). A recent single-arm enzalutamide clinical trial revealed that non-responders to enzalutamide treatment exhibits a basal lineage, such as reduced AR transcriptional activity and a neurogenic/stemness program, while a luminal lineage program was activated in responders (Alumkal et al., 2020), indicating that there is need to explore the specific factors that regulate de novo enzalutamide resistance.

\section{FACTORS GOVERNING CELLULAR PLASTICITY}

\section{Cell-Intrinsic Factors}

In the past decade, multiple independent studies unraveled the diverse spectrum of molecular and other environmental factors governing the PCa lineage plasticity. Dramatic differences in the gene expression and copy number alterations has been reported to co-exist between the prostate adenocarcinoma and the NEPC, often within the same tumor foci (Beltran et al., 2011). Moreover, comprehensive molecular characterization of the NEPC tumors revealed the significance of divergent clonal evolution. Under the influence of therapy, CRPC cells give rise to new clones owing to epithelial plasticity, with distinct molecular profiles and genetic aberrations. Initially, few molecular alterations occur that drive and select clones for the cellular plasticity, followed by a series of passenger alterations which may result in the emergence of therapy-resistance NEPC (Beltran et al., 2016).

Most of the prostatic small cell carcinomas (SCC) harbor the TMPRSS2-ERG gene rearrangement confirming its involvement in the carcinogenesis. Although, TMPRSS2-ERG fusion is not reported in the SCC of non-prostatic origins, such as lung and urinary bladder, indicating that this genetic event can be used as a molecular marker to establish the prostatic origin of metastatic SCC (Guo et al., 2011). Of note, NEPC foci often lack the expression of ERG protein in the tumors harboring TMPRSS2-ERG fusion, which reaffirms the reduced or absent androgen signaling. A classic example of this ambiguity is the NEPC cell line model, NCI-H660 which harbors TMPRSS2$E R G$ fusion, but lacks expression of ERG protein (Beltran et al., 2011). Furthermore, ERG oncoprotein suppresses the expression of NEPC related genes in PCa which is relieved upon inhibition of AR signaling (Mounir et al., 2015).

The mutational landscape of NEPC patients has identified the role of $R B 1$ loss and mutated/deleted TP53 in the SCC pathogenesis. In contrast to the CRPC-adenocarcinoma patients, CRPC-NE patients showed reduced frequency of genomic alterations associated with androgen receptor (AR), indicating the selection of AR-independent clonal subpopulation during NEPC progression (Beltran et al., 2016). Simultaneous aberration in various tumor suppressor genes (RB1, TP53, and/or PTEN) has been known to drive tumor plasticity in PCa (Aparicio et al., 2016). For instance, knockdown of TP53 and RB1 using short hairpin RNAs (shRNAs) in AR overexpressing LNCaP cells resulted in the enhanced expression of basal and neuroendocrine lineage markers thereby conferring resistance to anti-androgen therapy (Aparicio et al., 2016).

Overexpression of Aurora kinase A (AURKA) and oncogene $\mathrm{N}-\mathrm{Myc}$ (MYCN) due to gene amplification was found in NEPC cases, where both proteins cooperate in driving the NE-transdifferentiation. Although, being located on different chromosomes, the mechanism involved in their co-amplification in NEPC remains unknown, but certainly hints toward their usefulness as diagnostic markers for early intervention in the high-risk population (Beltran et al., 2011). Interestingly, this discovery formed the basis to use Aurora kinase A inhibitors for the treatment of NEPC patients harboring AURKA amplification (Beltran et al., 2019). Moreover, activated AKT1 and MYCN are also known to drive the transformation of prostate epithelial cells to adenocarcinoma and differentiation to NE-like phenotype (Lee et al., 2016). MYCN in cooperation with PRC2 complex member, EZH2 and other cofactors suppress the AR signaling and PRC2 target genes (Beltran et al., 2011; Dardenne et al., 2016; Lee et al., 2016). Apart from EZH2, other PRC1 containing 
proteins, such as members of CBX family have also been shown to be dysregulated in patient-tumor derived xenografts (PDX) and NEPC clinical samples, highlighting a role for dysregulated Polycomb Group (PcG)-mediated silencing during NE-transdifferentiation (Clermont et al., 2015).

Reduced expression of RE1 silencing transcription factor (REST), a master negative regulator of neuroendocrine differentiation accompanied with enrichment of the REST target NE-associated genes has been reported in the NEPC clinical samples (Lapuk et al., 2012). Interestingly, another member of REST transcriptional repressor complex, PHD finger protein 21A (PHF21A) is differentially spliced in NEPC cases compared to adenocarcinoma. PHDF21A loses the AT-hook domain which is involved in the DNA binding via alternative splicing (Lapuk et al., 2012). In LNCaP cells, androgen stimulation leads to co-occupancy of REST on the AR occupied chromatin regions and mediates transcriptional repression of a subset of genes. Further, siRNA mediated REST silencing leads to upregulation of genes associated with neuronal differentiation and maintenance of NE phenotype (Svensson et al., 2013). Moreover, activation of androgen signaling enhances REST protein levels by modulating the activity of $\beta$-TRCP ubiquitin ligase. Importantly, Casein kinase 1 (CK1) is known to phosphorylate REST and enhance the $\beta$-TRCP activity leading to ubiquitin-mediated proteasomal degradation of REST. Therefore, treatment of SPINK1-positive 22RV1 cells with CK1 inhibitor resulted in restoration of REST protein levels, accompanied with reduced SPINK1 levels and its oncogenic properties (Tiwari et al., 2020), thus emphasizing the repressive role of REST protein in the regulation of SPINK1 and disease progression toward NE-like phenotype.

Evaluation of the transcription factors involved in lineage plasticity in prostate tumors showed SRY-box transcription factor 2 (SOX2) to be highly upregulated in tumors with altered TP53 and RB1 (TP53 $3^{\text {Alt }}, \mathrm{RB1}{ }^{\mathrm{Alt}}$ ) compared to wildtype TP53 and $\mathrm{RB} 1$ (TP53 ${ }^{\mathrm{WT}}, \mathrm{RB1}{ }^{\mathrm{WT}}$ ) tumors. Furthermore, SOX2 silencing in the LNCaP cells overexpressing AR with inactivated RB1 and TP53 reversed the increased expression of basal (CK5, CK14, and TP63) and neuroendocrine (SYP, CHGA, and NSE) lineage markers induced due to TP53 and RB1 loss (Mu et al., 2017). Furthermore, the role of SOX2 has been reported in repressing adenocarcinoma specific genes by enhancing the expression and activity of lysine-specific demethylase 1A (LSD1/KDM1A) (Li et al., 2019), highlighting the potential of SOX2 as a lineage reprogramming factor in neuroendocrine prostate tumors. Moreover, a neural specific transcript variant of LSD1 also known as LSD1+8a, has been shown to be exclusively expressed in NEPC tissue samples and patient-derived xenograft samples, and LSD1+8a/SRRM4 co-upregulated gene signature was found to be exclusively activated in aggressive NEPC patient tumors, that are different from those regulated by the canonical LSD1 (Coleman et al., 2020). A recent study reported Serine Peptidase Inhibitor, Kazal type 1 (SPINK1) to be transcriptionally repressed by AR and its corepressor REST, and androgen deprivation resulted in its upregulation. Furthermore, SOX2 was shown to modulate the expression of SPINK1 during the NE-transdifferentiation of LNCaP cells (Tiwari et al., 2020). This study also confirmed the role of SPINK1 in EMT, stemness and NE-transdifferentiation.
Additionally, a subset of NEPC patients exhibit elevated levels of SPINK1, suggesting its role in the maintenance of the NE-like phenotype (Tiwari et al., 2020).

Metabolic reprogramming plays a crucial role in cancer progression and therapy-resistance (Hanahan and Weinberg, 2011). The ground-breaking discovery by Warburg suggested the preference of aerobic glycolysis over oxidative phosphorylation in cancer cells which primarily rely on the mitochondrial oxidative phosphorylation for adenosine 5'-triphosphate (ATP) generation. This resulted in the higher rate of glucose uptake and lactate production in presence of oxygen (Vander Heiden et al., 2009). Early clinical studies have shown that fluorodeoxyglucose (FDG)-PET imaging which is based on increased glucose uptake by cancer cells failed to detect naïve localized PCa (Effert et al., 1996), but can detect the advanced stage small cell prostate cancer (SCPC) (de Carvalho Flamini et al., 2010), highlighting the metabolic differences underlying the adenocarcinoma and SCPC. Moreover, the higher uptake of glucose has been associated with the elevated expression of Glucose Transporter 1 (GLUT1) in poorly differentiated hormone-independent PCa (Effert et al., 2004). It has also been observed that PCa switch to aerobic glycolysis only at the advanced stages of the disease progression and correlates with poor clinical outcomes (Pertega-Gomes et al., 2015). Of interest, the gene expression profile of NEPC patients showed glycolysis and lactic acid production as the most significantly upregulated pathways in these tumors (Choi et al., 2018). It has been shown that higher expression of the plasma membrane transporter monocarboxylate transporter 4 (MCT4) facilitated the enhanced secretion of lactic acid, while antisense oligonucleotides mediated silencing of MCT4 led to reduced lactic acid secretion, glucose metabolism and NEPC cell proliferation (Choi et al., 2018). Recently, reduced $\mathrm{PKC} \lambda / \iota$ has been reported in de novo and treatmentrelated NEPC differentiation, which resulted in upregulated mTORC1/ATF4/PHGDH and promoted serine biosynthesis, leading to increased S-adenosyl methionine (SAM). Moreover, higher mTORC1 activity, stronger nuclear ATF4 staining and increased expression of PHGDH was also detected in NEPC tumors compared to adenocarcinoma, suggesting the critical role of mTORC1/ATF4/PHGDH metabolic axis in increased cell proliferation and epigenetic reprogramming during NEPC development (Reina-Campos et al., 2019).

Numerous factors have been shown to be involved in maintaining the tumor cell plasticity (Table 1), however, more comprehensive in-depth studies are required to dissect the specific drivers which can be targeted for therapeutic implications.

\section{Cell-Extrinsic Factors}

The external cues along with the cell intrinsic factors, such as transcriptional and epigenetics regulation, are the key determinants for the tumor heterogeneity in PCa patients (Davies et al., 2018). The cell extrinsic factors constitute the tumor microenvironment which dictates the process of cellular plasticity in most of the malignancies including prostate (Yates, 2011). The concept of influence of microenvironment on tumor cells was initially proposed by an English surgeon, Stephen Paget, 
TABLE 1 | An overview of key molecular drivers involved in cell plasticity in the pathogenesis of prostate cancer.

\begin{tabular}{|c|c|c|c|}
\hline $\begin{array}{l}\text { Molecular } \\
\text { drivers }\end{array}$ & Regulatory mechanism & Phenotypic features & References \\
\hline \multicolumn{4}{|c|}{ EPITHELIAL-MESENCHYMAL TRANSITION (EMT) } \\
\hline $\mathrm{CDH} 1$ & Downregulated by Notch signaling & $\begin{array}{l}\text { Silencing } \mathrm{CDH} 1 \text { (E-Cad) promotes PCa cell migration, } \\
\text { drug-resistance and metastasis }\end{array}$ & $\begin{array}{l}\text { Wang et al., 2017; Loh } \\
\text { et al., } 2019\end{array}$ \\
\hline SOX9 & Regulated by Wnt/ $\beta$-catenin signaling & Enhances tumor cell proliferation and invasion & Wang et al., 2008 \\
\hline ZEB1 & Shows bidirectional negative feedback loop with AR & Mediates androgen deprivation induced EMT & Sun et al., 2012 \\
\hline ZEB2 & Differential regulation by AR & Potentiates cell invasion and migration & Jacob et al., 2014 \\
\hline SLUG & Androgen-responsive gene and AR coactivator & Facilitates PCa cell growth in androgen-deprived conditions & Wu et al., 2012 \\
\hline SNAIL & Transcriptionally repressed by AR & $\begin{array}{l}\text { Plays a critical role in ADT induced epithelial-mesenchymal } \\
\text { plasticity }\end{array}$ & Miao et al., 2017 \\
\hline CCL2 & Silencing AR elevates CCL2 levels and STAT3 signaling & Promotes metastasis via macrophage recruitment & $\begin{array}{l}\text { Izumi et al., 2013; Tsai } \\
\text { et al., } 2018\end{array}$ \\
\hline \multicolumn{4}{|l|}{ STEMNESS } \\
\hline ABCG2 & $\begin{array}{l}\text { Membrane transporter found on prostate cancer stem } \\
\text { cells }\end{array}$ & $\begin{array}{l}\text { Maintain proliferative potential under hypoxic conditions, and efflux } \\
\text { androgens }\end{array}$ & Huss et al., 2005 \\
\hline CD44 & $\begin{array}{l}\text { Cell-surface marker found on AR-independent basal } \\
\text { prostate cells }\end{array}$ & $\begin{array}{l}\text { CD44-positive PCa cells have high proliferative, clonogenic, } \\
\text { tumorigenic, and metastatic potential }\end{array}$ & $\begin{array}{l}\text { Liu et al., 1997; } \\
\text { Patrawala et al., } 2006\end{array}$ \\
\hline \multicolumn{4}{|c|}{ THERAPY-INDUCED CELLULAR PLASTICITY } \\
\hline SNAIL & PEG10 regulates SNAIL expression via TGF- $\beta$ signaling & $\begin{array}{l}\text { Elevated levels found in tumor after castration in xenografts model } \\
\text { and NEPC development }\end{array}$ & Akamatsu et al., 2015 \\
\hline ZEB1 & $\begin{array}{l}\text { Higher expression in castrated PTEN knockout mice and } \\
\text { NEPC models }\end{array}$ & $\begin{array}{l}\text { Induce stem cell-like properties and promotes } \\
\text { androgen-independence in } \mathrm{PCa}\end{array}$ & $\begin{array}{l}\text { Li et al., 2014; } \\
\text { Akamatsu et al., } 2015\end{array}$ \\
\hline SOX11 & Upregulated in Pten and Trp53 inactivated mice model & $\begin{array}{l}\text { Abiraterone treatment of Pten/Trp53 inactivated mice lead to } \\
\text { neuroendocrine differentiation }\end{array}$ & Zou et al., 2017 \\
\hline BRN2 & AR repressed gene and regulates SOX2 expression & $\begin{array}{l}\text { Key driver of aggressive tumor growth; higher levels found in } \\
\text { NEPC compared to CRPC and adenocarcinomas }\end{array}$ & Bishop et al., 2017 \\
\hline \multicolumn{4}{|c|}{ CELL-INTRINSIC FACTORS } \\
\hline AURKA & Amplified and overexpressed in NEPC & $\begin{array}{l}\text { Functionally cooperate with N-MYC and drive neuroendocrine } \\
\text { phenotype }\end{array}$ & $\begin{array}{l}\text { Beltran et al., } 2011 ; \\
\text { Lee et al., } 2016\end{array}$ \\
\hline MYCN & Amplified and overexpressed in NEPC & $\begin{array}{l}\text { Stabilizes AURKA, abrogates AR signaling, induces PRC2 } \\
\text { silencing and serves as an oncogenic driver of NEPC }\end{array}$ & $\begin{array}{l}\text { Beltran et al., 2011; } \\
\text { Dardenne et al., 2016; } \\
\text { Lee et al., } 2016\end{array}$ \\
\hline $\mathrm{EZH} 2$ & Highly expressed in advanced stage PCa and NEPC & Transforms the epigenetic landscape of PCa and NEPC & $\begin{array}{l}\text { Varambally et al., 2008; } \\
\text { Beltran et al., 2011; } \\
\text { Clermont et al., 2015; } \\
\text { Dardenne et al., } 2016\end{array}$ \\
\hline REST & Downregulated in NEPC & $\begin{array}{l}\text { Transcriptional corepressor of AR and implicated in NEPC } \\
\text { development }\end{array}$ & $\begin{array}{l}\text { Lapuk et al., 2012; } \\
\text { Svensson et al., 2013; } \\
\text { Tiwari et al., } 2020\end{array}$ \\
\hline SOX2 & $\begin{array}{l}\text { Overexpressed in NEPC tumors consistent with RB1 and } \\
\text { TP53 alterations }\end{array}$ & $\begin{array}{l}\text { Required for lineage plasticity and antiandrogen resistance } \\
\text { induced by inactivated RB1 and TP53 }\end{array}$ & $\begin{array}{l}\text { Bishop et al., 2017; Mu } \\
\text { et al., } 2017\end{array}$ \\
\hline SPINK1 & $\begin{array}{l}\text { Transcriptionally repressed by AR and REST and } \\
\text { regulated by SOX2 in androgen deprived condition }\end{array}$ & $\begin{array}{l}\text { Imparts cellular plasticity and maintenance of neuroendocrine } \\
\text { phenotype }\end{array}$ & Tiwari et al., 2020 \\
\hline $\mathrm{PKC} \lambda / \iota$ & Downregulated in NEPC & $\begin{array}{l}\text { Its loss promotes serine biosynthesis, resulting in metabolic } \\
\text { reprogramming to support cell proliferation and epigenetic } \\
\text { changes }\end{array}$ & $\begin{array}{l}\text { Reina-Campos et al., } \\
2019\end{array}$ \\
\hline \multicolumn{4}{|c|}{ CELL-EXTRINSIC FACTORS } \\
\hline TGF- $\beta$ & $\begin{array}{l}\text { Shows negative feedback loop with PMEPA1; cross talk } \\
\text { with CXCR4; acts via both SMAD-dependent and } \\
\text { independent pathways }\end{array}$ & Associated with PCa aggressiveness and bone metastasis & $\begin{array}{l}\text { Derynck and Zhang, } \\
\text { 2003; Bhowmick et al., } \\
\text { 2004; Ao et al., 2007; } \\
\text { Fournier et al., } 2015\end{array}$ \\
\hline IL-6 & Secreted by aggressive PCa cells & Elicits fibroblast activation and secrete MMPs & Giannoni et al., 2010 \\
\hline BMP6 & Secreted by PCa cells and show feedback loop with IL-6 & $\begin{array}{l}\text { Upregulates IL-6 expression from macrophages, leading to } \\
\text { neuroendocrine differentiation of PCa cells }\end{array}$ & Lee et al., 2011 \\
\hline $\begin{array}{l}\text { IL-1 family } \\
\text { genes }\end{array}$ & Secreted by prostate epithelial cells & $\begin{array}{l}\text { Induce secretion of proinflammatory cytokines (CXCL-1,-2,-3 } \\
\text { and IL-8) in stromal cells and facilitate cancer progression. }\end{array}$ & $\begin{array}{l}\text { Kogan-Sakin et al., } \\
2009\end{array}$ \\
\hline SPINK1 & $\begin{array}{l}\text { Regulated by NF-кB and C/EBP upon DNA damage in } \\
\text { stromal cells }\end{array}$ & $\begin{array}{l}\text { Serves as a senescence-associated secretory factor and a } \\
\text { non-invasive biomarker of therapeutically damaged tumor } \\
\text { microenvironment }\end{array}$ & Chen et al., 2018a \\
\hline
\end{tabular}


who laid the foundation that the conducive microenvironment is essential for the colonization of the disseminated tumor cells, also known as the seed and soil theory (Paget, 1889). The tumor microenvironment includes blood vessels, stromal cells namely, cancer-associated fibroblasts (CAFs), endothelial cells, neuroendocrine cells and infiltrating immune cells, growth factors and chemokines secreted by either tumor cells or stromal cells and many extracellular matrix proteins such as laminin, fibronectin, and collagen (Yates, 2011). Apart from the dynamic interaction between tumor and stromal cells, physical (elasticity and stiffness) and biochemical properties (protein composition) of the extracellular matrix (ECM), as well as access to nutrients and oxygen also governs the cellular plasticity of the tumor cells (Yates, 2011; Davies et al., 2018; Patel et al., 2019).

Among the different stromal cells, CAFs play a critical role in modulating the plasticity of the cancer cells. The CAFs are well-known to support tumor growth, resistance to therapy and metastasis by creating a tumor-promoting microenvironment for the cancer cells to proliferate, invade and evade the immune suppression (Cirri and Chiarugi, 2011). Moreover, CAFs mainly originate from the fibroblasts residing in tumor under the influence of the transforming growth factor (TGF- $\beta$ ) secreted by cancer cells (Massague, 2008; Bellomo et al., 2016). In addition, stromal cells such as pericytes or inflammatory cells may also transdifferentiate to CAFs via the process known as mesenchymal-to-mesenchymal transition (MMT) under the influence of TGF- $\beta$ and other cytokines secreted in the tumor microenvironment (Bellomo et al., 2016). Similar to cancer cells, the CAFs also produce TGF- $\beta$ which acts as an autocrine and paracrine factor and regulates the reorganization of the extracellular matrix and the interaction between tumor-stroma (Erdogan and Webb, 2017). Moreover, CAFs isolated from prostate carcinomas produce higher amounts of other cytokines namely, pro-inflammatory cytokines, interleukin-6 (IL6) and bone morphogenetic factor (BMP6), thereby promoting tumor progression (Doldi et al., 2015). There is a reciprocal interplay between CAFs and tumor cells, wherein tumor cells secrete IL6 and promotes CAFs to secrete matrix metalloproteases (MMPs) which in turn remodels the ECM, and further induces secretion of IL6 from tumor cells, thereby driving EMT. In addition, CAFs promote tumor forming ability and stemness when coimplanted with PCa cells in mice xenografts, and importantly, these tumor-repopulating cells were found to be CD44-positive and CD24-negative (Giannoni et al., 2010). The prostate stromal cells are also known to secrete proinflammatory and cancerpromoting chemokines such as CXCL-1, CXCL-2, CXCL-3, and interleukin (IL)-8, which are the key regulators of cellular plasticity, culminating in inflammation, and PCa progression

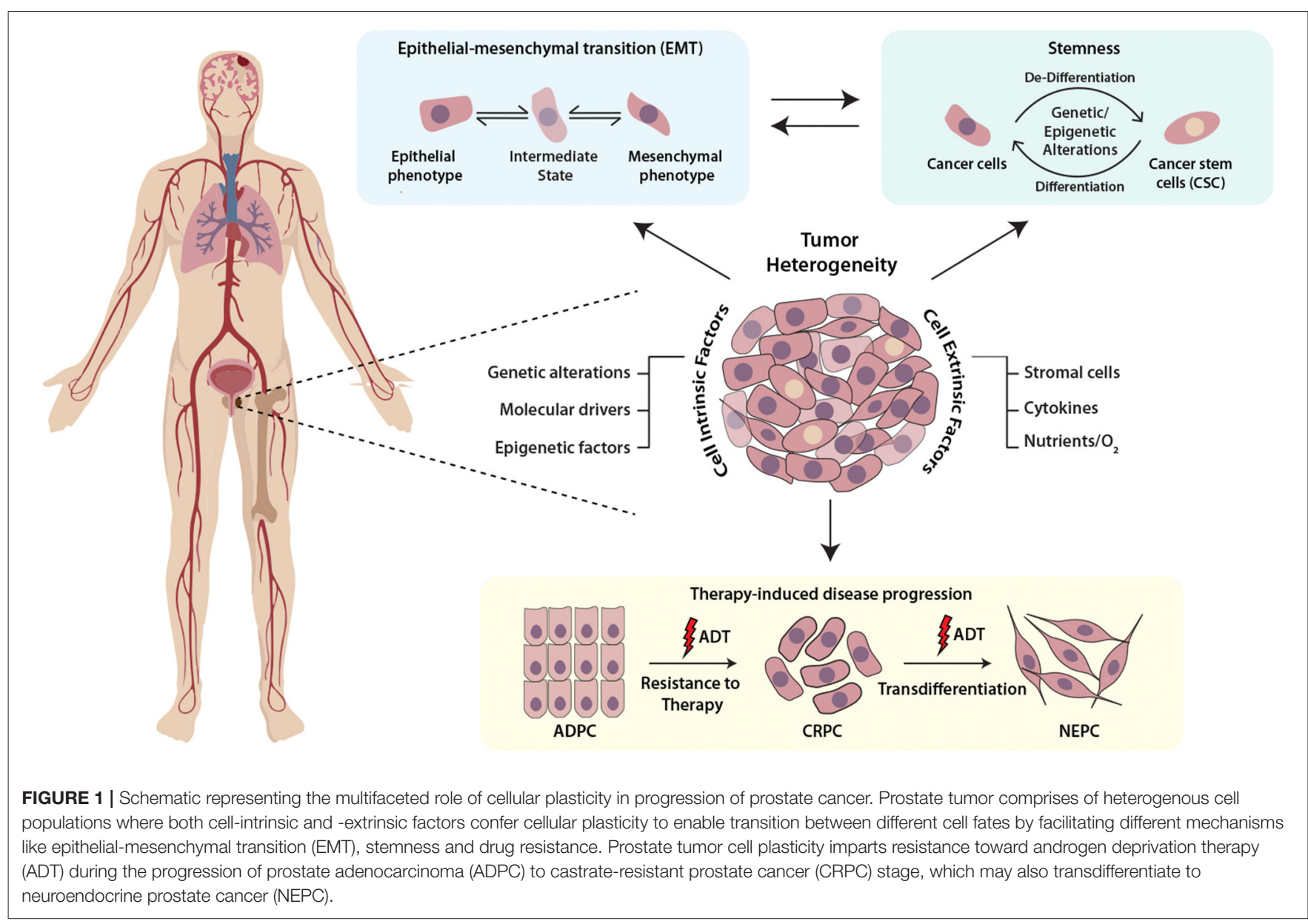


TABLE 2 | Therapeutic interventions targeting key molecular drivers involved in the cellular plasticity of prostate cancer.

\begin{tabular}{|c|c|c|c|c|}
\hline Inhibitor & Target & Mechanism of action & Clinical trial and status & References \\
\hline $\begin{array}{l}\text { Siltuximab } \\
\text { (CNTO 328) }\end{array}$ & IL6 & $\begin{array}{l}\text { Chimeric monoclonal antibody which } \\
\text { neutralizes IL6 and prevents STAT3 activation }\end{array}$ & $\begin{array}{l}\text { NCT00401765; } \\
\text { Completed }\end{array}$ & Hudes et al., 2013 \\
\hline $\begin{array}{l}\text { Apitolisib } \\
\text { (GDC-0980) }\end{array}$ & $\begin{array}{l}\mathrm{PI} 3 \mathrm{~K} \text { and } \mathrm{mTOR} \\
\text { kinase }\end{array}$ & Inhibits PI3K-AKT-mTOR signaling axis & $\begin{array}{l}\text { NCT00854152; } \\
\text { Completed }\end{array}$ & Dolly et al., 2016 \\
\hline CPI-1205 & $\mathrm{EZH} 2$ & $\begin{array}{l}\text { Cofactor-competitive inhibitor of wild type and } \\
\text { mutant EZH2 catalytic activity }\end{array}$ & NCT03480646; Active & Taplin et al., 2019 \\
\hline GSK2816126 & $\mathrm{EZH} 2$ & $\begin{array}{l}\text { Inhibits EZH2 activity and reduces global } \\
\text { methylation of H3K27me } 3 \text { marks }\end{array}$ & NCT02082977; Terminated & Yap et al., 2016 \\
\hline $\begin{array}{l}\text { Rovalpituzumab } \\
\text { Tesirine (SC16LD6.5) }\end{array}$ & DLL3 & $\begin{array}{l}\text { Antibody-drug conjugate targeting DLL3 (a } \\
\text { Notch ligand) }\end{array}$ & $\begin{array}{l}\text { NCT02674568; } \\
\text { Completed }\end{array}$ & Puca et al., 2019 \\
\hline
\end{tabular}

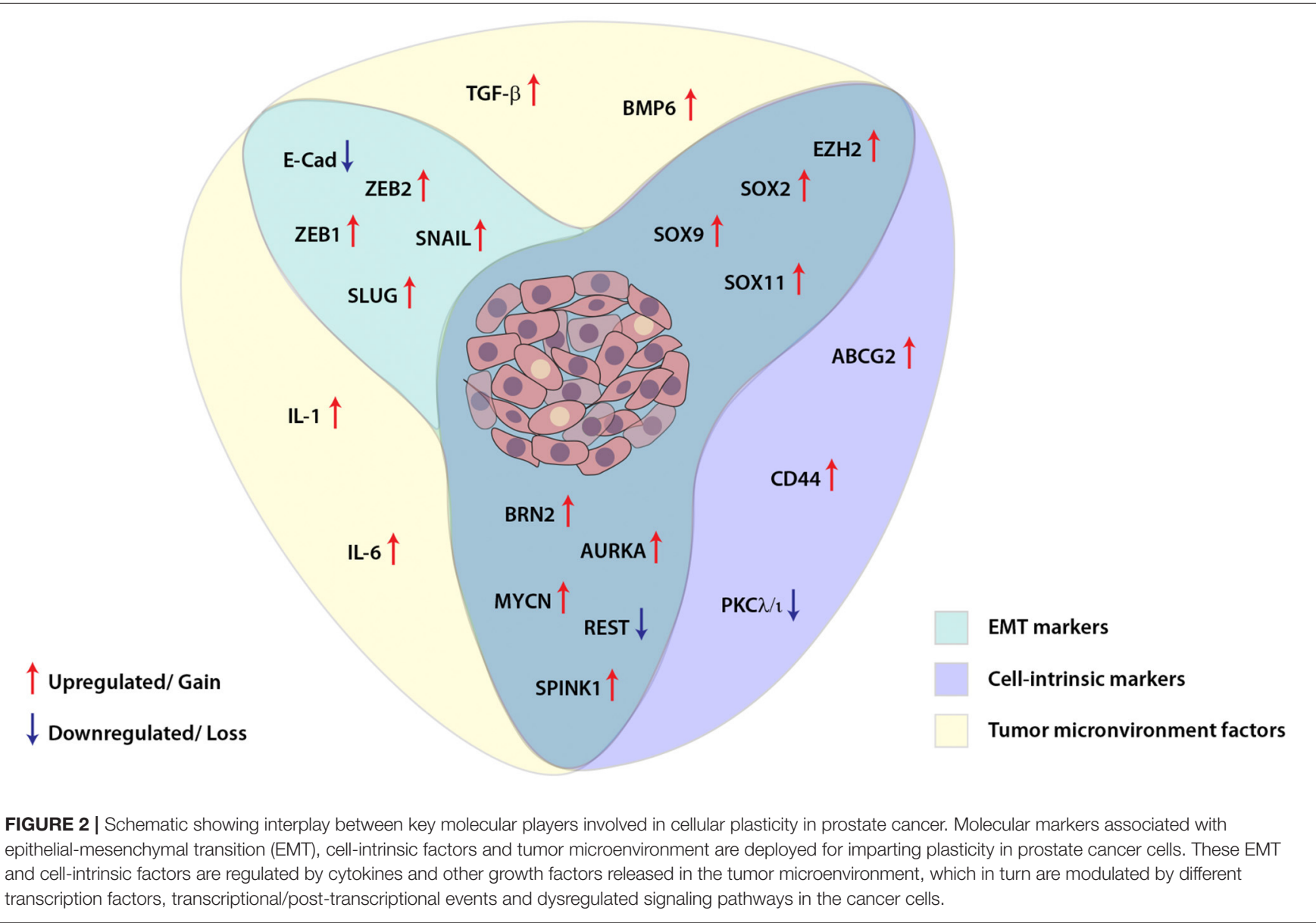


(Kogan-Sakin et al., 2009). The prostatic CAFs also produce stromal glutamine as a result of epigenetic reprogramming and contribute to NE-transdifferentiation (Mishra et al., 2018). Interestingly, it has been known that genotoxic effect of chemoand radiation therapies prompt stromal cells to produce SPINK1 as a secretory factor, which induces EGFR-mediated signaling and imparts chemoresistance in the adjacent prostate tumor cells (Chen et al., 2018a).

Tumor associated macrophages (TAMs) are also known to play important role in regulating cellular plasticity and NE-transdifferentiation. For instance, BPH-1 cells when cocultured with THP-1 cells differentiated macrophages, led to increased expression of mesenchymal markers, such as N-Cad, Snail, and TGF- $\beta 2$, and this phenotype was abrogated upon incubating with anti-TGF- $\beta 2$ neutralizing antibody (Lu et al., 2012). Further, conditioned media collected from macrophages induce expression of NE-marker and parathyroid hormonerelated peptide (PTHrP) in LNCaP and TRAMP-C2 cells. In this feedback loop, BMP6 secreted from the PCa cells induce production of IL6 from the macrophages, which in turn stimulates the NE-transdifferentiation of PCa cells (Lee et al., 2011).

Mounting evidence highlights the role of the physiochemical properties such as hypoxia or oxidative stress as key regulators of cellular plasticity in tumors. For instance, hypoxic stress leads to the upregulation of Hypoxia-inducible factor 1$\alpha$ (HIF $1 \alpha)$, which in cooperation with FOXA2, drives mesenchymal reprogramming and NE-transdifferentiation in PCa cells ( $\mathrm{Li}$ et al., 2016). Another report indicates that hypoxia leads to reduced expression of transcriptional repressor REST, which in turn leads to hypoxia-induced neuroendocrine differentiation, followed by activation of associated AMPK pathway and autophagy (Lin et al., 2016). Multi-disciplinary approaches such as mathematical modeling and bioengineering tools, would allow fostering a hypoxic niche for exploring the events and mechanisms involved in adaptation of aggressive cancer behaviors, and would provide cues to disrupt the signaling pathways involved in crosstalk between cancer cells and tumor microenvironment (Figure 1).

\section{TARGETING CELLULAR PLASTICITY AND ITS CLINICAL IMPLICATIONS}

Current studies are focused on targeting the markers and pathways involved in upholding the cellular plasticity in prostate cancer. Previous investigations have recommended the use of aurora kinase inhibitors in NMYC overexpressing prostate cancer, wherein it disrupts the N-Myc-AURKA complex and results in reduced tumor burden (Beltran et al., 2011; Dardenne et al., 2016; Lee et al., 2016). However, recent phase II clinical trials of AURKA inhibitor (NCT01799278), alisertib used for the treatment of metastatic NEPC patients showed efficacy in select cases (Beltran et al., 2019). Furthermore, $\mathrm{N}-\mathrm{Myc}$ has been shown to cooperate with EZH2 and play critical role in changing the epigenetic landscape of $A R$ and
$\mathrm{N}-\mathrm{Myc}$ target genes during NEPC transition. Elevated levels of N-Myc showed enhanced sensitivity to EZH2 catalytic SET domain inhibitor GSK503 in mice harboring N-Myc overexpressing 22RV1 xenografts (Dardenne et al., 2016). The EZH2 inhibitor (CPI-1205) combined with enzalutamide or abiraterone/prednisone are currently under phase Ib/II clinical trials (NCT03480646) for the treatment of metastatic CRPC cases. Recently, one of the homeobox transcription factors, ONECUT2 has been shown to synergize with hypoxia signaling in promoting NEPC transition. Importantly, hypoxia-activated pro-drug TH-302 showed remarkable reduction of the tumor growth in PDX models with higher levels of ONECUT2, suggesting it as a promising treatment strategy for NEPC (Guo et al., 2019). A recent study showed the therapeutic potential of rovalpituzumab tesirine (SC16LD6.5) in NEPC cases with higher expression of Delta-like ligand 3 (DLL3) (Puca et al., 2019). There is no direct effective therapy for targeting cellular plasticity, however, therapeutic modalities targeting the known molecular drivers of NEPC using small molecule inhibitors in combination with immune checkpoint inhibitors are under development (Table 2).

\section{CONCLUSION}

Similar to other malignancies, in prostate cancer as well, cellular plasticity is induced as a result of different contributing factors and governs a diverse set of characteristics which are involved in facilitating tumor dissemination, metastatic spread to distant sites and conferring resistance toward therapy (Figure 2). Despite the clinical benefits of ADT for the treatment of PCa, emerging evidence has suggested that ADT propels the cancer cells toward therapy-induced resistance and emergence of aggressive AR-independent variants of prostate cancer. Therefore, understanding the dynamics of tumor cell plasticity during transition from androgen responsive to androgen non-responsive state holds a prime importance in targeting the PCa progression. Also, in order to discover new therapeutic avenues enormous efforts are required to explore the underlying mechanisms involved in ADT mediated resistance or chemotherapeutic drug resistance of cancer cells in the clinical spectrum of prostate cancer stages. In conclusion, therapies against the cell plasticity, alone or in combination with AR-antagonists might prove effective for the clinical management of advanced stage CRPC or NEPC patients.

\section{AUTHOR CONTRIBUTIONS}

$\mathrm{RT}$, NM, and BA reviewed the literature and contributed to manuscript writing. All authors contributed to the article and approved the submitted version.

\section{FUNDING}

BA acknowledges the research funding from the Wellcome Trust/DBT India Alliance Fellowship (IA/I(S)/12/2/ 
500635 to BA), the Department of Biotechnology (BT/PR8675/GET/119/1/2015 to BA) and the Science and Engineering Research Board, Ministry of Science and
Technology, Government of India (EMR/2016/005273 to BA). NM acknowledges fellowship support from the University Grants Commission (UGC), Government of India.

\section{REFERENCES}

Aggarwal, R., Huang, J., Alumkal, J. J., Zhang, L., Feng, F. Y., Thomas, G. V., et al. (2018). Clinical and genomic characterization of treatment-emergent small-cell neuroendocrine prostate cancer: a multi-institutional prospective study. J. Clin. Oncol. 36, 2492-2503. doi: 10.1200/JCO.2017.77.6880

Akamatsu, S., Wyatt, A. W., Lin, D., Lysakowski, S., Zhang, F., Kim, S., et al. (2015). The placental gene PEG10 promotes progression of neuroendocrine prostate cancer. Cell Rep. 12, 922-936. doi: 10.1016/j.celrep.2015.07.012

Alumkal, J. J., Sun, D., Lu, E., Beer, T. M., Thomas, G. V., Latour, E., et al. (2020). Transcriptional profiling identifies an androgen receptor activity-low, stemness program associated with enzalutamide resistance. Proc. Natl. Acad. Sci. U.S.A. 117, 12315-12323. doi: 10.1073/pnas.1922207117

Antonarakis, E. S., Lu, C., Wang, H., Luber, B., Nakazawa, M., Roeser, J. C., et al. (2014). AR-V7 and resistance to enzalutamide and abiraterone in prostate cancer. N. Engl. J. Med. 371, 1028-1038. doi: 10.1056/NEJMoa1315815

Ao, M., Franco, O. E., Park, D., Raman, D., Williams, K., and Hayward, S. W. J. C.R. (2007). Cross-talk between paracrine-acting cytokine and chemokine pathways promotes malignancy in benign human prostatic epithelium. Cancer Res. 67, 4244-4253. doi: 10.1158/0008-5472.CAN-06-3946

Aparicio, A. M., Shen, L., Tapia, E. L. N., Lu, J.-F., Chen, H.-C., Zhang, J., et al. (2016). Combined tumor suppressor defects characterize clinically defined aggressive variant prostate. Cancers (Basel). 22, 1520-1530. doi: 10.1158/1078-0432.CCR-15-1259

Arora, V. K., Schenkein, E., Murali, R., Subudhi, S. K., Wongvipat, J., Balbas, M. D., et al. (2013). Glucocorticoid receptor confers resistance to antiandrogens by bypassing androgen receptor blockade. Cell 155, 1309-1322. doi: 10.1016/j.cell.2013.11.012

Barnett, P., Arnold, R. S., Mezencev, R., Chung, L. W., Zayzafoon, M., and OderoMarah, V. (2011). Snail-mediated regulation of reactive oxygen species in ARCaP human prostate cancer cells. Biochem. Biophys. Res. Commun. 404, 34-39. doi: 10.1016/j.bbrc.2010.11.044

Bellomo, C., Caja, L., and Moustakas, A. J. B. J. O. C. (2016). Transforming growth factor $\beta$ as regulator of cancer stemness and metastasis. Br. J. Cancer 115, 761-769. doi: 10.1038/bjc.2016.255

Beltran, H., and Demichelis, F. (2015). Intrapatient heterogeneity in prostate cancer. Nat. Rev. Urol. 12, 430-431. doi: 10.1038/nrurol.2015.182

Beltran, H., Oromendia, C., Danila, D. C., Montgomery, B., Hoimes, C., Szmulewitz, R. Z., et al. (2019). A phase II trial of the Aurora kinase A inhibitor alisertib for patients with castration-resistant and neuroendocrine prostate cancer: efficacy and biomarkers. Clin. Cancer Res. 25, 43-51. doi: 10.1158/1078-0432.CCR-18-1912

Beltran, H., Prandi, D., Mosquera, J. M., Benelli, M., Puca, L., Cyrta, J., et al. (2016). Divergent clonal evolution of castration-resistant neuroendocrine prostate cancer. Nat. Med. 22, 298-305. doi: 10.1038/nm.4045

Beltran, H., Rickman, D. S., Park, K., Chae, S. S., Sboner, A., Macdonald, T. Y., et al. (2011). Molecular characterization of neuroendocrine prostate cancer and identification of new drug targets. Cancer Discov. 1, 487-495. doi: 10.1158/2159-8290.CD-11-0130

Berx, G., Cleton-Jansen, A. M., Nollet, F., De Leeuw, W. J., Van De Vijver, M., Cornelisse, C., et al. (1995). E-cadherin is a tumour/invasion suppressor gene mutated in human lobular breast cancers. EMBO J. 14, 6107-6115. doi: 10.1002/j.1460-2075.1995.tb00301.x

Bhatia, V., and Ateeq, B. (2019). Molecular underpinnings governing genetic complexity of ETS-fusion-negative prostate cancer. Trends Mol. Med. 25, 1024-1038. doi: 10.1016/j.molmed.2019.07.001

Bhowmick, N. A., Chytil, A., Plieth, D., Gorska, A. E., Dumont, N., Shappell, S., et al. (2004). TGF- $\beta$ signaling in fibroblasts modulates the oncogenic potential of adjacent epithelia. Science 303, 848-851. doi: 10.1126/science.1090922

Bianco-Miotto, T., Chiam, K., Buchanan, G., Jindal, S., Day, T. K., Thomas, M., et al. (2010). Global levels of specific histone modifications and an epigenetic gene signature predict prostate cancer progression and development. Cancer Epidemiol. Biomarkers Prev. 19, 2611-2622. doi: 10.1158/1055-9965.EPI-10-0555

Bishop, J. L., Thaper, D., Vahid, S., Davies, A., Ketola, K., Kuruma, H., et al. (2017). The master neural transcription factor BRN2 is an androgen receptorsuppressed driver of neuroendocrine differentiation in prostate cancer. Cancer Discov. 7, 54-71. doi: 10.1158/2159-8290.CD-15-1263

Blau, H. M., Pavlath, G. K., Hardeman, E. C., Chiu, C. P., Silberstein, L., Webster, S. G., et al. (1985). Plasticity of the differentiated state. Science 230, 758-766. doi: $10.1126 /$ science. 2414846

Blee, A., and Huang, H. (2019). Lineage plasticity-mediated therapy resistance in prostate cancer. Asian J. Androl. 21, 241-248. doi: 10.4103/aja.aja_41_18

Boumahdi, S., and de Sauvage, F. J. (2019). The great escape: tumour cell plasticity in resistance to targeted therapy. Nat Rev Drug Discov. 19, 39-56. doi: 10.1038/s41573-019-0044-1

Boutros, P. C., Fraser, M., Harding, N. J., De Borja, R., Trudel, D., Lalonde, E., et al. (2015). Spatial genomic heterogeneity within localized, multifocal prostate cancer. Nat. Genet. 47, 736-745. doi: 10.1038/ng.3315

Boyd, L. K., Mao, X., and Lu, Y.-J. (2012). The complexity of prostate cancer: genomic alterations and heterogeneity. Nat. Rev. Urol. 9, 652-664. doi: 10.1038/nrurol.2012.185

Brocks, D., Assenov, Y., Minner, S., Bogatyrova, O., Simon, R., Koop, C., et al. (2014). Intratumor DNA methylation heterogeneity reflects clonal evolution in aggressive prostate cancer. Cell Rep. 8, 798-806. doi: 10.1016/j.celrep.2014.06.053

Cancer Genome Atlas Research, N. (2015). The molecular taxonomy of primary prostate cancer. Cell 163, 1011-1025. doi: 10.1016/j.cell.2015. 10.025

Celia-Terrassa, T., Meca-Cortes, O., Mateo, F., Martinez De Paz, A., Rubio, N., Arnal-Estape, A., et al. (2012). Epithelial-mesenchymal transition can suppress major attributes of human epithelial tumor-initiating cells. J. Clin. Invest. 122, 1849-1868. doi: 10.1172/JCI59218

Chen, C. D., Welsbie, D. S., Tran, C., Baek, S. H., Chen, R., Vessella, R., et al. (2004). Molecular determinants of resistance to antiandrogen therapy. Nat. Med. 10, 33-39. doi: 10.1038/nm972

Chen, F., Long, Q., Fu, D., Zhu, D., Ji, Y., Han, L., et al. (2018a). Targeting SPINK1 in the damaged tumour microenvironment alleviates therapeutic resistance. Nat. Commun. 9, 1-19. doi: 10.1038/s41467-018-06860-4

Chen, G., Karzai, F., Madan, R. A., Cordes, L. M., Bilusic, M., Owens, H., et al. (2018b). CRLX101 plus olaparib in patients with metastatic castration-resistant prostate cancer. J. Clin. Oncol. 36 (Suppl. 15), TPS5096. doi: 10.1200/JCO.2018.36.15_suppl.TPS5096

Cheng, L., Nagabhushan, M., Pretlow, T. P., Amini, S. B., and Pretlow, T. G. (1996). Expression of E-cadherin in primary and metastatic prostate cancer. Am. J. Pathol. 148, 1375-1380.

Cher, M. L., Bova, G. S., Moore, D. H., Small, E. J., Carroll, P. R., Pin, S. S., et al. (1996). Genetic alterations in untreated metastases and androgenindependent prostate cancer detected by comparative genomic hybridization and allelotyping. Cancer Res. 56, 3091-3102.

Choi, S. Y. C., Ettinger, S. L., Lin, D., Xue, H., Ci, X., Nabavi, N., et al. (2018). Targeting MCT 4 to reduce lactic acid secretion and glycolysis for treatment of neuroendocrine prostate cancer. Cancer Med. 7, 3385-3392. doi: $10.1002 /$ cam 4.1587

Cirri, P., and Chiarugi, P. (2011). Cancer associated fibroblasts: the dark side of the coin. Am. J. Cancer Res. 1, 482-497.

Clegg, N. J., Wongvipat, J., Joseph, J. D., Tran, C., Ouk, S., Dilhas, A., et al. (2012). ARN-509: a novel antiandrogen for prostate cancer treatment. Cancer Res. 72, 1494-1503. doi: 10.1158/0008-5472.CAN-11-3948

Clermont, P.-L., Lin, D., Crea, F., Wu, R., Xue, H., Wang, Y., et al. (2015). Polycomb-mediated silencing in neuroendocrine prostate cancer. Clin. Epigenetics 7:40. doi: 10.1186/s13148-015-0074-4 
Clevers, H. (2006). Wnt/beta-catenin signaling in development and disease. Cell 127, 469-480. doi: 10.1016/j.cell.2006.10.018

Coleman, D. J., Sampson, D. A., Sehrawat, A., Kumaraswamy, A., Sun, D., Wang, Y., et al. (2020). Alternative splicing of LSD1+8a in neuroendocrine prostate cancer is mediated by SRRM4. Neoplasia 22, 253-262. doi: 10.1016/j.neo.2020.04.002

Collins, A. T., Berry, P. A., Hyde, C., Stower, M. J., and Maitland, N. J. J. C.R. (2005). Prospective identification of tumorigenic prostate cancer stem cells. Cancer Res, 65, 10946-10951. doi: 10.1158/0008-5472.CAN-05-2018

Cooke, P. S., Young, P., and Cunha, G. R. (1991). Androgen receptor expression in developing male reproductive organs. Endocrinology 128, 2867-2873. doi: 10.1210/endo-128-6-2867

Culig, Z., and Santer, F. R. (2014). Androgen receptor signaling in prostate cancer. Cancer Metastasis Rev. 33, 413-427. doi: 10.1007/s10555-0139474-0

Cunha, G. R., Donjacour, A. A., Cooke, P. S., Mee, S., Bigsby, R. M., Higgins, S. J., et al. (1987). The endocrinology and developmental biology of the prostate. Endocr. Rev. 8, 338-362. doi: 10.1210/edrv-8-3-338

Dai, Y., Wu, Z., Lang, C., Zhang, X., He, S., Yang, Q., et al. (2019). Copy number gain of ZEB1 mediates a double-negative feedback loop with miR$33 a-5 p$ that regulates EMT and bone metastasis of prostate cancer dependent on TGF-beta signaling. Theranostics 9, 6063-6079. doi: 10.7150/thno. 36735

Dardenne, E., Beltran, H., Benelli, M., Gayvert, K., Berger, A., Puca, L., et al. (2016). N-Myc induces an EZH2-mediated transcriptional program driving neuroendocrine prostate cancer. Cancer Cell 30, 563-577. doi: 10.1016/j.ccell.2016.09.005

Davies, A. H., Beltran, H., and Zoubeidi, A. (2018). Cellular plasticity and the neuroendocrine phenotype in prostate cancer. Nat. Rev. Urol. 15, 271-286. doi: 10.1038/nrurol.2018.22

de Bono, J. S., Logothetis, C. J., Molina, A., Fizazi, K., North, S., Chu, L., et al. (2011). Abiraterone and increased survival in metastatic prostate cancer. $N$. Engl. J. Med. 364, 1995-2005. doi: 10.1056/NEJMoa1014618

de Carvalho Flamini, R., Yamaga, L., Mello, M. E., Wagner, J., Livorsi Da Cunha, M., Osawa, A., et al. (2010). F-18 FDG PET/CT imaging in small cell prostate cancer. Clin. Nucl. Med. 35, 452-453. doi: 10.1097/RLU.0b013e3181db4ce9

Dempke, W. C. M., Fenchel, K., Uciechowski, P., and Chevassut, T. (2017). Targeting developmental pathways: the achilles heel of cancer? Oncology 93, 213-223. doi: 10.1159/000478703

Derynck, R., and Zhang, Y. E. (2003). Smad-dependent and smadindependent pathways in TGF-beta family signalling. Nature 425, 577-584. doi: 10.1038/nature02006

Djavan, B., Susani, M., Bursa, B., Basharkhah, A., Simak, R., and Marberger, M. (1999). Predictability and significance of multifocal prostate cancer in the radical prostatectomy specimen. Tech. Urol. 5, 139-142. doi: 10.1016/S0022-5347(01)62084-6

Doldi, V., Callari, M., Giannoni, E., D’aiuto, F., Maffezzini, M., Valdagni, R., et al. (2015). Integrated gene and miRNA expression analysis of prostate cancer associated fibroblasts supports a prominent role for interleukin-6 in fibroblast activation. Oncotarget 6, 31441-31460. doi: 10.18632/oncotarget.5056

Dolly, S. O., Wagner, A. J., Bendell, J. C., Kindler, H. L., Krug, L. M., Seiwert, T. Y., et al. (2016). Phase I study of apitolisib (GDC-0980), dual phosphatidylinositol-3-kinase and mammalian target of rapamycin kinase inhibitor, in patients with advanced solid tumors. Clin. Cancer Res. 22, 2874-2884. doi: 10.1158/1078-0432.CCR-15-2225

Effert, P., Beniers, A. J., Tamimi, Y., Handt, S., and Jakse, G. (2004). Expression of glucose transporter 1 (Glut-1) in cell lines and clinical specimens from human prostate adenocarcinoma. Anticancer Res. 24, 3057-3063.

Effert, P. J., Bares, R., Handt, S., Wolff, J. M., Bull, U., and Jakse, G. J. T. J. O. U. (1996). Metabolic imaging of untreated prostate cancer by positron emission tomography with sup 18 fluorine-labeled deoxyglucose. J. Urol. 155, 994-998. doi: 10.1016/S0022-5347(01)66366-3

Ellis, L., and Loda, M. (2015). Advanced neuroendocrine prostate tumors regress to stemness. Proc. Natl. Acad. Sci. U.S.A. 112, 14406-14407. doi: $10.1073 /$ pnas. 1519151112

Erdogan, B., and Webb, D. J. (2017). Cancer-associated fibroblasts modulate growth factor signaling and extracellular matrix remodeling to regulate tumor metastasis. Biochem. Soc. Trans. 45, 229-236. doi: 10.1042/BST20160387
Figiel, S., Vasseur, C., Bruyere, F., Rozet, F., Maheo, K., and Fromont, G. (2017). Clinical significance of epithelial-mesenchymal transition markers in prostate cancer. Hum. Pathol. 61, 26-32. doi: 10.1016/j.humpath.2016.10.013

Flavahan, W. A., Gaskell, E., and Bernstein, B. E. (2017). Epigenetic plasticity and the hallmarks of cancer. Science 357:eaal2380. doi: 10.1126/science.aal2380

Floor, S., Van Staveren, W., Larsimont, D., Dumont, J. E., and Maenhaut, C. J. O. (2011). Cancer cells in epithelial-to-mesenchymal transition and tumorpropagating-cancer stem cells: distinct, overlapping or same populations. Oncogene 30, 4609-4621. doi: 10.1038/onc.2011.184

Fournier, P. G., Juárez, P., Jiang, G., Clines, G. A., Niewolna, M., Kim, H. S., et al. (2015). The TGF- $\beta$ signaling regulator PMEPA1 suppresses prostate cancer metastases to bone. Cancer Cell 27, 809-821. doi: 10.1016/j.ccell.2015.04.009

Friedmann-Morvinski, D., and Verma, I. M. (2014). Dedifferentiation and reprogramming: origins of cancer stem cells. EMBO Rep. 15, 244-253. doi: 10.1002/embr.201338254

Frixen, U. H., Behrens, J., Sachs, M., Eberle, G., Voss, B., Warda, A., et al. (1991). E-cadherin-mediated cell-cell adhesion prevents invasiveness of human carcinoma cells. J. Cell Biol. 113, 173-185. doi: 10.1083/jcb.113.1.173

Garraway, I. P., Sun, W., Tran, C. P., Perner, S., Zhang, B., Goldstein, A. S., et al. (2010). Human prostate sphere-forming cells represent a subset of basal epithelial cells capable of glandular regeneration in vivo. Prostate 70, 491-501. doi: $10.1002 /$ pros. 21083

Gelmann, E. P. (2002). Molecular biology of the androgen receptor. J. Clin. Oncol. 20, 3001-3015. doi: 10.1200/JCO.2002.10.018

Giannoni, E., Bianchini, F., Masieri, L., Serni, S., Torre, E., Calorini, L., et al. (2010). Reciprocal activation of prostate cancer cells and cancer-associated fibroblasts stimulates epithelial-mesenchymal transition and cancer stemness. Cancer Res. 70, 6945-6956. doi: 10.1158/0008-5472.CAN-10-0785

Goldstein, A. S., Huang, J., Guo, C., Garraway, I. P., and Witte, O. N. (2010). Identification of a cell of origin for human prostate cancer. Science 329, 568-571. doi: 10.1126/science.1189992

Graham, T. R., Zhau, H. E., Odero-Marah, V. A., Osunkoya, A. O., Kimbro, K. S., Tighiouart, M., et al. (2008). Insulin-like growth factorI-dependent up-regulation of ZEB1 drives epithelial-to-mesenchymal transition in human prostate cancer cells. Cancer Res. 68, 2479-2488. doi: 10.1158/0008-5472.CAN-07-2559

Grasso, C. S., Wu, Y. M., Robinson, D. R., Cao, X., Dhanasekaran, S. M., Khan, A. P., et al. (2012). The mutational landscape of lethal castration-resistant prostate cancer. Nature 487, 239-243. doi: 10.1038/nature11125

Gregory, C. W., He, B., Johnson, R. T., Ford, O. H., Mohler, J. L., French, F. S., et al. (2001). A mechanism for androgen receptor-mediated prostate cancer recurrence after androgen deprivation therapy. Cancer Res. 61, 4315-4319.

Guilford, P. (1999). E-cadherin downregulation in cancer: fuel on the fire? Mol. Med. Today 5, 172-177. doi: 10.1016/S1357-4310(99)01461-6

Guo, C., Liu, H., Zhang, B. H., Cadaneanu, R. M., Mayle, A. M., and Garraway, I. P. (2012). Epcam, CD44, and CD49f distinguish sphere-forming human prostate basal cells from a subpopulation with predominant tubule initiation capability. PLoS ONE 7:e34219. doi: 10.1371/journal.pone.0034219

Guo, C. C., Dancer, J. Y., Wang, Y., Aparicio, A., Navone, N. M., Troncoso, P., et al. (2011). TMPRSS2-ERG gene fusion in small cell carcinoma of the prostate. Hum. Pathol. 42, 11-17. doi: 10.1016/j.humpath.2010.05.026

Guo, H., Ci, X., Ahmed, M., Hua, J. T., Soares, F., Lin, D., et al. (2019). ONECUT2 is a driver of neuroendocrine prostate cancer. Nat. Commun. 10, 1-13. doi: 10.1038/s41467-018-08133-6

Hanahan, D., and Weinberg, R. A. (2011). Hallmarks of cancer: the next generation. Cell 144, 646-674. doi: 10.1016/j.cell.2011.02.013

Hudes, G., Tagawa, S. T., Whang, Y. E., Qi, M., Qin, X., Puchalski, T. A., et al. (2013). A phase 1 study of a chimeric monoclonal antibody against interleukin-6, siltuximab, combined with docetaxel in patients with metastatic castration-resistant prostate cancer. Invest. New Drugs 31, 669-676. doi: 10.1007/s10637-012-9857-z

Huss, W. J., Gray, D. R., Greenberg, N. M., Mohler, J. L., and Smith, G. J. J. C.R. (2005). Breast cancer resistance protein-mediated efflux of androgen in putative benign and malignant prostate stem cells. Cancer Res. 65, 6640-6650. doi: 10.1158/0008-5472.CAN-04-2548

Izumi, K., Fang, L. Y., Mizokami, A., Namiki, M., Li, L., Lin, W. J., et al. (2013). Targeting the androgen receptor with siRNA promotes prostate cancer metastasis through enhanced macrophage recruitment via 
CCL2/CCR2-induced STAT3 activation. EMBO Mol. Med. 5, 1383-1401. doi: $10.1002 / \mathrm{emmm} .201202367$

Jacob, S., Nayak, S., Fernandes, G., Barai, R., Menon, S., Chaudhari, U., et al. (2014). Androgen receptor as a regulator of ZEB2 expression and its implications in epithelial-to-mesenchymal transition in prostate cancer. Endocr. Relat. Cancer 21, 473-486. doi: 10.1530/ERC-13-0514

Jennbacken, K., Tešan, T., Wang, W., Gustavsson, H., Damber, J.-E., and Welen, K. (2010). N-cadherin increases after androgen deprivation and is associated with metastasis in prostate cancer. Endocr. Relat. Cancer 17, 469-479. doi: 10.1677/ERC-10-0015

Kalluri, R., and Weinberg, R. A. (2009). The basics of epithelial-mesenchymal transition. J. Clin. Invest. 119, 1420-1428. doi: 10.1172/JCI39104

Karthaus, W. R., Iaquinta, P. J., Drost, J., Gracanin, A., Van Boxtel, R., Wongvipat, J., et al. (2014). Identification of multipotent luminal progenitor cells in human prostate organoid cultures. Cell 159, 163-175. doi: 10.1016/j.cell.2014. 08.017

Kogan-Sakin, I., Cohen, M., Paland, N., Madar, S., Solomon, H., Molchadsky, A., et al. (2009). Prostate stromal cells produce CXCL-1, CXCL-2, CXCL-3 and IL-8 in response to epithelia-secreted IL-1. Carcinogenesis 30, 698-705. doi: 10.1093/carcin/bgp043

Kong, D., Banerjee, S., Ahmad, A., Li, Y., Wang, Z., Sethi, S., et al. (2010). Epithelial to mesenchymal transition is mechanistically linked with stem cell signatures in prostate cancer cells. PLoS ONE 5:e12445. doi: 10.1371/journal.pone.0012445

Kreso, A., and Dick, J. E. J. C. S. C. (2014). Evolution of the cancer stem cell model. Cell Stem Cell 14, 275-291. doi: 10.1016/j.stem.2014.02.006

Kung, P. P., Bingham, P., Brooun, A., Collins, M., Deng, Y. L., Dinh, D., et al. (2018). Optimization of orally bioavailable enhancer of zeste homolog 2 (EZH2) inhibitors using ligand and property-based design strategies: identification of development candidate (R)-5,8-dichloro-7-(methoxy(oxetan-3-yl)methyl)2-((4-methoxy-6-methyl-2-oxo-1,2- dihydropyridin-3-yl)methyl)-3,4dihydroisoquinolin-1(2H)-one (PF-06821497). J. Med. Chem. 61, 650-665. doi: 10.1021/acs.jmedchem.7b01375

Lapuk, A. V., Wu, C., Wyatt, A. W., Mcpherson, A., Mcconeghy, B. J., Brahmbhatt, S., et al. (2012). From sequence to molecular pathology, and a mechanism driving the neuroendocrine phenotype in prostate cancer. J. Pathol. 227, 286-297. doi: 10.1002/path.4047

Lee, G. T., Kwon, S. J., Lee, J. H., Jeon, S. S., Jang, K. T., Choi, H. Y., et al. (2011). Macrophages induce neuroendocrine differentiation of prostate cancer cells via BMP6-IL6 loop. Prostate 71, 1525-1537. doi: 10.1002/pros.21369

Lee, J. K., Phillips, J. W., Smith, B. A., Park, J. W., Stoyanova, T., Mccaffrey, E. F., et al. (2016). N-Myc drives neuroendocrine prostate cancer initiated from human prostate epithelial cells. Cancer Cell 29, 536-547. doi: 10.1016/j.ccell.2016.03.001

Li, H., Wang, L., Li, Z., Geng, X., Li, M., Tang, Q., et al. (2019). SOX2 has dual functions as a regulator in the progression of neuroendocrine prostate cancer. J. Tech. Methods Pathol. 100, 570-582. doi: 10.1038/s41374-019-0343-5

Li, J. J., and Shen, M. M. (2019). Prostate stem cells and cancer stem cells. Cold Spring Harb. Perspect. Med. 9:ea030395. doi: 10.1101/cshperspect.a030395

Li, M., Wang, Y. X., Luo, Y., Zhao, J., Li, Q., Zhang, J., et al. (2016). Hypoxia inducible factor-1alpha-dependent epithelial to mesenchymal transition under hypoxic conditions in prostate cancer cells. Oncol. Rep 36, 521-527. doi: $10.3892 /$ or.2016.4766

Li, P., Wang, J., Chu, M., Zhang, K., Yang, R., Gao, W.-Q. J. E. B., and Medicine (2014). Zebl promotes androgen independence of prostate cancer via induction of stem cell-like properties. 239, 813-822. doi: 10.1177/1535370214538727

Lin, D., Wyatt, A. W., Xue, H., Wang, Y., Dong, X., Haegert, A., et al. (2014). High fidelity patient-derived xenografts for accelerating prostate cancer discovery and drug development. Cancer Res. 74, 1272-1283. doi: 10.1158/0008-5472.CAN-13-2921-T

Lin, T. H., Izumi, K., Lee, S. O., Lin, W. J., Yeh, S., and Chang, C. (2013). Antiandrogen receptor ASC-J9 versus anti-androgens MDV3100 (Enzalutamide) or Casodex (Bicalutamide) leads to opposite effects on prostate cancer metastasis via differential modulation of macrophage infiltration and STAT3-CCL2 signaling. Cell Death Dis. 4:e764. doi: 10.1038/cddis.2013.270

Lin, T. P., Chang, Y. T., Lee, S. Y., Campbell, M., Wang, T. C., Shen, S. H., et al. (2016). REST reduction is essential for hypoxia-induced neuroendocrine differentiation of prostate cancer cells by activating autophagy signaling. Oncotarget 7, 26137-26151. doi: 10.18632/oncotarget.8433
Liu, A. Y., True, L. D., Latray, L., Nelson, P. S., Ellis, W. J., Vessella, R. L., et al. (1997). Cell-cell interaction in prostate gene regulation and cytodifferentiation. Proc. Natl. Acad. Sci. U.S.A. 94, 10705-10710. doi: 10.1073/pnas.94.20.10705

Liu, W., Laitinen, S., Khan, S., Vihinen, M., Kowalski, J., Yu, G., et al. (2009). Copy number analysis indicates monoclonal origin of lethal metastatic prostate cancer. Nat. Med. 15:559. doi: 10.1038/nm.1944

Loh, C.-Y., Chai, J. Y., Tang, T. F., Wong, W. F., Sethi, G., Shanmugam, M. K., et al. (2019). The E-cadherin and N-cadherin switch in epithelial-to-mesenchymal transition: Signaling, therapeutic implications, and challenges. Cells 8:1118. doi: $10.3390 /$ cells 8101118

Lu, T., Lin, W. J., Izumi, K., Wang, X., Xu, D., Fang, L. Y., et al. (2012). Targeting androgen receptor to suppress macrophage-induced EMT and benign prostatic hyperplasia (BPH) development. Mol. Endocrinol. 26, 1707-1715. doi: 10.1210/me.2012-1079

Lu, W., and Kang, Y. (2019). Epithelial-mesenchymal plasticity in cancer progression and metastasis. Dev. Cell 49, 361-374. doi: 10.1016/j.devcel.2019.04.010

Marjanovic, N. D., Weinberg, R. A., and Chaffer, C. L. (2013). Cell plasticity and heterogeneity in cancer. Clin. Chem. 59, 168-179. doi: $10.1373 /$ clinchem.2012.184655

Massague, J. (2008). TGFbeta in Cancer. Cell 134, 215-230. doi: 10.1016/j.cell.2008.07.001

McKeithen, D., Graham, T., Chung, L. W., and Odero-Marah, V. (2010). Snail transcription factor regulates neuroendocrine differentiation in $\mathrm{LNCaP}$ prostate cancer cells. Prostate 70, 982-992. doi: 10.1002/pros.21132

Miao, L., Yang, L., Li, R., Rodrigues, D. N., Crespo, M., Hsieh, J.-T., et al. (2017). Disrupting androgen receptor signaling induces Snail-mediated epithelialmesenchymal plasticity in prostate cancer. Cancer Res. 77, 3101-3112. doi: 10.1158/0008-5472.CAN-16-2169

Mishra, R., Haldar, S., Placencio, V., Madhav, A., Rohena-Rivera, K., Agarwal, P., et al. (2018). Stromal epigenetic alterations drive metabolic and neuroendocrine prostate cancer reprogramming. J. Clin. Invest. 128, 4472-4484. doi: 10.1172/JCI99397

Mounir, Z., Lin, F., Lin, V., Korn, J., Yu, Y., Valdez, R., et al. (2015). TMPRSS2: ERG blocks neuroendocrine and luminal cell differentiation to maintain prostate cancer proliferation. Oncogene 34:3815. doi: 10.1038/onc.2014.308

Mu, P., Zhang, Z., Benelli, M., Karthaus, W. R., Hoover, E., Chen, C.C., et al. (2017). SOX2 promotes lineage plasticity and antiandrogen resistance in TP53-and RB1-deficient prostate cancer. Science 355, 84-88. doi: 10.1126/science.aah4307

Nauseef, J. T., and Henry, M. D. (2011). Epithelial-to-mesenchymal transition in prostate cancer: paradigm or puzzle? Nat. Rev. Urol. 8, 428-439. doi: $10.1038 /$ nrurol.2011.85

Nieto, M. A. (2013). Epithelial plasticity: a common theme in embryonic and cancer cells. Science 342:1234850. doi: 10.1126/science.1234850

Nouri, M., Caradec, J., Lubik, A. A., Li, N., Hollier, B. G., Takhar, M., et al. (2017). Therapy-induced developmental reprogramming of prostate cancer cells and acquired therapy resistance. Oncotarget 8, 18949-18967. doi: 10.18632/oncotarget. 14850

Onder, T. T., Gupta, P. B., Mani, S. A., Yang, J., Lander, E. S., and Weinberg, R. A. (2008). Loss of E-cadherin promotes metastasis via multiple downstream transcriptional pathways. Cancer Res. 68, 3645-3654. doi: 10.1158/0008-5472.CAN-07-2938

Orellana-Serradell, O., Herrera, D., Castellon, E. A., and Contreras, H. R. (2018). The transcription factor ZEB1 promotes an aggressive phenotype in prostate cancer cell lines. Asian J. Androl. 20, 294-299. doi: 10.4103/aja.aja_61_17

Padmanaban, V., Krol, I., Suhail, Y., Szczerba, B. M., Aceto, N., Bader, J. S., et al. (2019). E-cadherin is required for metastasis in multiple models of breast cancer. Nature 573, 439-444. doi: 10.1038/s41586-019$1526-3$

Paget, S. (1889). The distribution of secondary growths in cancer of the breast. Lancet 133, 571-573. doi: 10.1016/S0140-6736(00)49915-0

Palanisamy, N., Ateeq, B., Kalyana-Sundaram, S., Pflueger, D., Ramnarayanan, K., Shankar, S., et al. (2010). Rearrangements of the RAF kinase pathway in prostate cancer, gastric cancer and melanoma. Nat. Med 16, 793-798. doi: $10.1038 / \mathrm{nm} .2166$

Palapattu, G. S., Wu, C., Silvers, C. R., Martin, H. B., Williams, K., Salamone, L., et al. (2009). Selective expression of CD44, a putative prostate cancer stem cell 
marker, in neuroendocrine tumor cells of human prostate cancer. Prostate 69, 787-798. doi: 10.1002/pros.20928

Patel, G. K., Chugh, N., and Tripathi, M. (2019). Neuroendocrine differentiation of prostate cancer-an intriguing example of tumor evolution at play. Cancers (Basel) 11:1405. doi: 10.3390/cancers11101405

Patrawala, L., Calhoun, T., Schneider-Broussard, R., Li, H., Bhatia, B., Tang, S., et al. (2006). Highly purified CD44+ prostate cancer cells from xenograft human tumors are enriched in tumorigenic and metastatic progenitor cells. Oncogene 25, 1696-1708. doi: 10.1038/sj.onc.1209327

Pertega-Gomes, N., Felisbino, S., Massie, C. E., Vizcaino, J. R., Coelho, R., Sandi, C., et al. (2015). A glycolytic phenotype is associated with prostate cancer progression and aggressiveness: a role for monocarboxylate transporters as metabolic targets for therapy. J. Pathol. 236, 517-530. doi: 10.1002/path.4547

Plaks, V., Kong, N., and Werb, Z. (2015). The cancer stem cell niche: how essential is the niche in regulating stemness of tumor cells? Cell Stem Cell 16, 225-238. doi: 10.1016/j.stem.2015.02.015

Poli, V., Fagnocchi, L., and Zippo, A. (2018). Tumorigenic cell reprogramming and cancer plasticity: interplay between signaling, microenvironment, and epigenetics. Stem Cells Int. 2018:4598195. doi: 10.1155/2018/4598195

Puca, L., Gavyert, K., Sailer, V., Conteduca, V., Dardenne, E., Sigouros, M., et al. (2019). Delta-like protein 3 expression and therapeutic targeting in neuroendocrine prostate cancer. Sci. Transl. Med. 11:eaav0891. doi: 10.1126/scitranslmed.aav0891

Qi, M., Hu, J., Cui, Y., Jiao, M., Feng, T., Li, X., et al. (2019). CUL4B promotes prostate cancer progression by forming positive feedback loop with SOX4. Oncogenesis 8:23. doi: 10.1038/s41389-019-0131-5

Qin, J., Liu, X., Laffin, B., Chen, X., Choy, G., Jeter, C. R., et al. (2012). The PSA(-/lo) prostate cancer cell population harbors self-renewing long-term tumor-propagating cells that resist castration. Cell Stem Cell 10, 556-569. doi: 10.1016/j.stem.2012.03.009

Reina-Campos, M., Linares, J. F., Duran, A., Cordes, T., L'hermitte, A., Badur, M. G., et al. (2019). Increased serine and one-carbon pathway metabolism by $\mathrm{PKC} \lambda / \iota$ deficiency promotes neuroendocrine prostate cancer. Cancer Cell 35, 385-400.e389. doi: 10.1016/j.ccell.2019.01.018

Ren, D., Wang, M., Guo, W., Huang, S., Wang, Z., Zhao, X., et al. (2014). Doublenegative feedback loop between ZEB2 and miR-145 regulates epithelialmesenchymal transition and stem cell properties in prostate cancer cells. Cell Tissue Res. 358, 763-778. doi: 10.1007/s00441-014-2001-y

Robinson, D., Van Allen, E. M., Wu, Y.-M., Schultz, N., Lonigro, R. J., Mosquera, J.-M., et al. (2015). Integrative clinical genomics of advanced prostate cancer. Cell 161, 1215-1228. doi: 10.1016/j.cell.2015.05.001

Rothman, J., and Jarriault, S. (2019). Developmental Plasticity and Cellular Reprogramming in Caenorhabditis elegans. Genetics 213, 723-757. doi: 10.1534/genetics.119.302333

Rybak, A. P., He, L., Kapoor, A., Cutz, J. C., and Tang, D. (2011). Characterization of sphere-propagating cells with stem-like properties from DU145 prostate cancer cells. Biochim. Biophys. Acta 1813, 683-694. doi: 10.1016/j.bbamcr.2011.01.018

Rybak, A. P., and Tang, D. (2013). SOX2 plays a critical role in EGFR-mediated selfrenewal of human prostate cancer stem-like cells. Cell. Signal 25, 2734-2742. doi: 10.1016/j.cellsig.2013.08.041

Schafer, J. M., Lehmann, B. D., Gonzalez-Ericsson, P. I., Marshall, C. B., Beeler, J. S., Redman, L. N., et al. (2020). Targeting MYCN-expressing triple-negative breast cancer with BET and MEK inhibitors. Sci. Transl. Med. 12:eaaw8275. doi: 10.1126/scitranslmed.aaw8275

Scher, H. I., Beer, T. M., Higano, C. S., Anand, A., Taplin, M. E., Efstathiou, E., et al. (2010). Antitumour activity of MDV3100 in castrationresistant prostate cancer: a phase 1-2 study. Lancet 375, 1437-1446. doi: 10.1016/S0140-6736(10)60172-9

Seligson, D. B., Horvath, S., Shi, T., Yu, H., Tze, S., Grunstein, M., et al. (2005). Global histone modification patterns predict risk of prostate cancer recurrence. Nature 435, 1262-1266. doi: 10.1038/nature03672

Shiota, M., Yokomizo, A., Takeuchi, A., Imada, K., Kashiwagi, E., Song, Y., et al. (2014). Inhibition of protein kinase C/Twist1 signaling augments anticancer effects of androgen deprivation and enzalutamide in prostate cancer. Clin. Cancer Res. 20, 951-961. doi: 10.1158/1078-0432.CCR-13-1809

Soundararajan, R., Paranjape, A. N., Maity, S., Aparicio, A., and Mani, S. A. (2018). EMT, stemness and tumor plasticity in aggressive variant neuroendocrine prostate cancers. Biochim. Biophys. Acta Rev. Cancer 1870, 229-238. doi: 10.1016/j.bbcan.2018.06.006

Stylianou, N., Lehman, M. L., Wang, C., Fard, A. T., Rockstroh, A., Fazli, L., et al. (2019). A molecular portrait of epithelial-mesenchymal plasticity in prostate cancer associated with clinical outcome. Oncogene 38, 913-934. doi: 10.1038/s41388-018-0488-5

Sun, Y., Wang, B.-E., Leong, K. G., Yue, P., Li, L., Jhunjhunwala, S., et al. (2012). Androgen deprivation causes epithelial-mesenchymal transition in the prostate: implications for androgen-deprivation therapy. Cancer Res. 72, 527-536. doi: 10.1158/0008-5472.CAN-11-3004

Svensson, C., Ceder, J., Iglesias-Gato, D., Chuan, Y.-C., Pang, S. T., Bjartell, A., et al. (2013). REST mediates androgen receptor actions on gene repression and predicts early recurrence of prostate cancer. Nucleic Acids Res. 42, 999-1015. doi: 10.1093/nar/gkt921

Tan, M. H., Li, J., Xu, H. E., Melcher, K., and Yong, E. L. (2015). Androgen receptor: structure, role in prostate cancer and drug discovery. Acta Pharmacol. Sin. 36, 3-23. doi: 10.1038/aps.2014.18

Tang, Y., Parmakhtiar, B., Simoneau, A. R., Xie, J., Fruehauf, J., Lilly, M., et al. (2011). Lycopene enhances docetaxel's effect in castration-resistant prostate cancer associated with insulin-like growth factor I receptor levels. Neoplasia 13, 108-119. doi: 10.1593/neo.101092

Taplin, M.-E., Hussain, A., Shah, S., Shore, N. D., Agrawal, M., Clark, W., et al. (2019). ProSTAR: a phase Ib/II study of CPI-1205, a small molecule inhibitor of $\mathrm{EZH} 2$, combined with enzalutamide $(\mathrm{E})$ or abiraterone/prednisone $(\mathrm{A} / \mathrm{P})$ in patients with metastatic castration-resistant prostate cancer (mCRPC). J. Clin. Oncol. 37:TPS335. doi: 10.1200/JCO.2019.37.7_suppl.TPS335

Taplin, M. E., Bubley, G. J., Shuster, T. D., Frantz, M. E., Spooner, A. E., Ogata, G. K., et al. (1995). Mutation of the androgen-receptor gene in metastatic androgen-independent prostate cancer. N. Engl. J. Med. 332, 1393-1398. doi: 10.1056/NEJM199505253322101

Taylor, R. A., Toivanen, R., Frydenberg, M., Pedersen, J., Harewood, L., Australian Prostate Cancer, B., et al. (2012). Human epithelial basal cells are cells of origin of prostate cancer, independent of CD133 status. Stem Cells 30, 1087-1096. doi: 10.1002/stem.1094

Thiery, J. P., Acloque, H., Huang, R. Y., and Nieto, M. A. (2009). Epithelialmesenchymal transitions in development and disease. Cell 139, 871-890. doi: 10.1016/j.cell.2009.11.007

Tian, X., Nguyen, M., Foote, H. P., Caster, J. M., Roche, K. C., Peters, C. G., et al. (2017). CRLX101, a nanoparticle-drug conjugate containing camptothecin, improves rectal cancer chemoradiotherapy by inhibiting DNA repair and HIFlalpha. Cancer Res. 77, 112-122. doi: 10.1158/0008-5472.CAN15-2951

Tiwari, R., Manzar, N., Bhatia, V., Yadav, A., Nengroo, M. A., Datta, D., et al. (2020). Androgen deprivation upregulates SPINK1 expression and potentiates cellular plasticity in prostate cancer. Nat. Commun. 11:384. doi: 10.1038/s41467-019-14184-0

Tomlins, S. A., Rhodes, D. R., Perner, S., Dhanasekaran, S. M., Mehra, R., Sun, X. W., et al. (2005). Recurrent fusion of TMPRSS2 and ETS transcription factor genes in prostate cancer. Science 310, 644-648. doi: 10.1126/science.1117679

Tomlins, S. A., Rhodes, D. R., Yu, J., Varambally, S., Mehra, R., Perner, S., et al. (2008). The role of SPINK1 in ETS rearrangement-negative prostate cancers. Cancer Cell 13, 519-528. doi: 10.1016/j.ccr.2008.04.016

Tsai, J. H., and Yang, J. (2013). Epithelial-mesenchymal plasticity in carcinoma metastasis. Genes Dev. 27, 2192-2206. doi: 10.1101/gad.225 334.113

Tsai, Y.-C., Chen, W.-Y., Abou-Kheir, W., Zeng, T., Yin, J. J., Bahmad, H., et al. (2018). Androgen deprivation therapy-induced epithelial-mesenchymal transition of prostate cancer through downregulating SPDEF and activating CCL2. Biochim. Biophys. Acta Mol. Basis Dis. 1864, 1717-1727. doi: 10.1016/j.bbadis.2018.02.016

Tsuji, T., Ibaragi, S., Shima, K., Hu, M. G., Katsurano, M., Sasaki, A., et al. (2008). Epithelial-mesenchymal transition induced by growth suppressor p12CDK2AP1 promotes tumor cell local invasion but suppresses distant colony growth. Cancer Res. 68, 10377-10386. doi: 10.1158/0008-5472.CAN-08-1444

Van De Wijngaart, D. J., Dubbink, H. J., Van Royen, M. E., Trapman, J., and Jenster, G. (2012). Androgen receptor coregulators: recruitment via the coactivator binding groove. Mol. Cell. Endocrinol. 352, 57-69. doi: 10.1016/j.mce.2011.08.007 
Vander Heiden, M. G., Cantley, L. C., and Thompson, C. B. (2009). Understanding the Warburg effect: the metabolic requirements of cell proliferation. Science 324, 1029-1033. doi: 10.1126/science.1160809

Varambally, S., Cao, Q., Mani, R. S., Shankar, S., Wang, X., Ateeq, B., et al. (2008). Genomic loss of microRNA-101 leads to overexpression of histone methyltransferase EZH2 in cancer. Science 322, 1695-1699. doi: 10.1126/science.1165395

Varga, J., and Greten, F. R. (2017). Cell plasticity in epithelial homeostasis and tumorigenesis. Nat. Cell Biol. 19, 1133-1141. doi: 10.1038/ncb3611

Vitkin, N., Nersesian, S., Siemens, D. R., and Koti, M. (2019). The tumor immune contexture of prostate cancer. Front. Immunol. 10:603. doi: 10.3389/fimmu.2019.00603

Wagers, A. J., and Weissman, I. L. (2004). Plasticity of adult stem cells. Cell 116, 639-648. doi: 10.1016/S0092-8674(04)00208-9

Wang, H., Leav, I., Ibaragi, S., Wegner, M., Hu, G.-F., Lu, M. L., et al. (2008). SOX9 is expressed in human fetal prostate epithelium and enhances prostate cancer invasion. Cancer Res. 68, 1625-1630. doi: 10.1158/0008-5472.CAN-07-5915

Wang, H., and Unternaehrer, J. J. (2019). Epithelial-mesenchymal transition and cancer stem cells: at the crossroads of differentiation and dedifferentiation. Dev. Dyn. 248, 10-20. doi: 10.1002/dvdy.24678

Wang, W., Wang, L., Mizokami, A., Shi, J., Zou, C., Dai, J., et al. (2017). Downregulation of E-cadherin enhances prostate cancer chemoresistance via Notch signaling. Chin J. Cancer 36:35. doi: 10.1186/s40880-017-0203-x

Wang, Z. A., and Shen, M. M. (2011). Revisiting the concept of cancer stem cells in prostate cancer. Oncogene 30, 1261-1271. doi: 10.1038/onc.2010.530

Wang, Z. A., Toivanen, R., Bergren, S. K., Chambon, P., and Shen, M. M. (2014). Luminal cells are favored as the cell of origin for prostate cancer. Cell Rep. 8, 1339-1346. doi: 10.1016/j.celrep.2014.08.002

Wellner, U., Schubert, J., Burk, U. C., Schmalhofer, O., Zhu, F., Sonntag, A., et al. (2009). The EMT-activator ZEB1 promotes tumorigenicity by repressing stemness-inhibiting microRNAs. Nat. Cell Biol. 11, 1487-1495. doi: $10.1038 /$ ncb1998

Williams, E. D., Gao, D., Redfern, A., and Thompson, E. W. (2019). Controversies around epithelial-mesenchymal plasticity in cancer metastasis. Nat. Rev. Cancer 19, 716-732. doi: 10.1038/s41568-019-0213-x

Wu, K., Gore, C., Yang, L., Fazli, L., Gleave, M., Pong, R.-C., et al. (2012). Slug, a unique androgen-regulated transcription factor, coordinates androgen receptor to facilitate castration resistance in prostate cancer. Mol. Endocrinol. 26, 1496-1507. doi: 10.1210/me.2011-1360

Yadav, S. S., Stockert, J. A., Hackert, V., Yadav, K. K., and Tewari, A. K. (2018). Intratumor heterogeneity in prostate cancer. Urol. Oncol. 36, 349-360. doi: 10.1016/j.urolonc.2018.05.008

Yap, T. A., Johnson, P. W. M., Winter, J., Leonard, J., Giulino-Roth, L., Horner, T., et al. (2016). A phase I, open-label study of GSK2816126, an enhancer of zeste homolog 2 (EZH2) inhibitor, in patients with relapsed/refractory diffuse large B-cell lymphoma (DLBCL), transformed follicular lymphoma (tFL), other non-Hodgkin's lymphomas (NHL), multiple myeloma (MM) and solid tumor. J. Clin. Oncol. 34(Suppl 15), TPS2595. doi: 10.1200/JCO.2016.34.15_suppl.TPS2595

Yates, C. (2011). "Prostate tumor cell plasticity: a consequence of the microenvironment," in Human Cell Transformation (New York, NY: Springer), 81-90

Yates, C. C., Shepard, C. R., Stolz, D. B., and Wells, A. (2007). Coculturing human prostate carcinoma cells with hepatocytes leads to increased expression of E-cadherin. Br. J. Cancer 96, 1246-1252. doi: 10.1038/sj.bjc.66 03700

Yuan, S., Norgard, R. J., and Stanger, B. Z. (2019). Cellular plasticity in cancer. Cancer Discov. 9, 837-851. doi: 10.1158/2159-8290.CD-19-0015

Zhang, Q., Helfand, B. T., Jang, T. L., Zhu, L. J., Chen, L., Yang, X. J., et al. (2009). Nuclear factor-kappaB-mediated transforming growth factor-betainduced expression of vimentin is an independent predictor of biochemical recurrence after radical prostatectomy. Clin. Cancer Res. 15, 3557-3567. doi: 10.1158/1078-0432.CCR-08-1656

Zhao, H., Thong, A., Nolley, R., Reese, S. W., Santos, J., Ingels, A., et al. (2013). Patient-derived tissue slice grafts accurately depict response of highrisk primary prostate cancer to androgen deprivation therapy. J. Transl. Med. 11:199. doi: 10.1186/1479-5876-11-199

Zhifang, M., Liang, W., Wei, Z., Bin, H., Rui, T., Nan, W., et al. (2015). The androgen receptor plays a suppressive role in epithelial-mesenchymal transition of human prostate cancer stem progenitor cells. BMC Biochem. 16:13. doi: 10.1186/s12858-015-0042-9

Zhu, M.-L., and Kyprianou, N. (2010). Role of androgens and the androgen receptor in epithelial-mesenchymal transition and invasion of prostate cancer cells. FASEB J. 24, 769-777. doi: 10.1096/fj.09-136994

Zou, M., Toivanen, R., Mitrofanova, A., Floch, N., Hayati, S., Sun, Y., et al. (2017). Transdifferentiation as a mechanism of treatment resistance in a mouse model of castration-resistant prostate cancer. Cancer Discov. 7, 736-749. doi: 10.1158/2159-8290.CD-16-1174

Conflict of Interest: The authors declare that the research was conducted in the absence of any commercial or financial relationships that could be construed as a potential conflict of interest.

Copyright (c) 2020 Tiwari, Manzar and Ateeq. This is an open-access article distributed under the terms of the Creative Commons Attribution License (CC BY). The use, distribution or reproduction in other forums is permitted, provided the original author(s) and the copyright owner(s) are credited and that the original publication in this journal is cited, in accordance with accepted academic practice. No use, distribution or reproduction is permitted which does not comply with these terms. 